\title{
Long-Term Monitoring and Analysis of Age-Related Changes on Autonomic Nervous Function
}

\author{
Kenichi Itao1,2, Makoto Komazawa1, Zhiwei Luo ${ }^{3}$, Hiroyuki Kobayashi² \\ ${ }^{1}$ WINFrontier Co. Ltd., Tokyo, Japan \\ ${ }^{2}$ Juntendo University, Tokyo, Japan \\ ${ }^{3}$ Organization of Advanced Science and Technology, Kobe University, Kobe, Japan \\ Email: kenichi.itao@winfrontier.com
}

How to cite this paper: Itao, K., Komazawa, M., Luo, Z.W. and Kobayashi, H. (2017) Long-Term Monitoring and Analysis of Age-Related Changes on Autonomic Nervous Function. Health, 9, 323-344. https://doi.org/10.4236/health.2017.92023

Received: December 21, 2016

Accepted: February 18, 2017

Published: February 21, 2017

Copyright () 2017 by authors and Scientific Research Publishing Inc. This work is licensed under the Creative Commons Attribution International License (CC BY 4.0).

http://creativecommons.org/licenses/by/4.0/

c) (i) Open Access

\begin{abstract}
This study used a small wearable heart rate sensor to monitor the daily autonomic function of 600 subjects from across all age groups over a prolonged period of time. The results indicated that the LF/HF ratio (Heart Rate Variability, LF: frequencies between $0.04 \mathrm{~Hz}-0.15 \mathrm{~Hz}, \mathrm{HF}$ : frequencies between $0.15 \mathrm{~Hz}-0.4 \mathrm{~Hz}$ ) an indicator of balance in the autonomic nervous system, tended to peak for subjects in their 40 's and decline thereafter. This conceivably may be partially due to the causes for concern and stress changing and/or declining for the group aged 50-plus. A decline in diurnal variation of autonomic nervous activity was also exhibited in subjects aged 50 and up, showing a tendency for decline in the function of rising sympathetic nerve activity particularly in the morning. It is conceivable that this stems from a decline in the responsiveness of the autonomic nervous system. Subjects in the 50-plus group furthermore exhibited a tendency for declining variation in autonomic nervous activity between sleeping and waking hours. This phenomenon was consistent with the tendency for there to be a rise in wake after sleep onset coupled with a decline in slow-wave sleep in middle- to old-age.
\end{abstract}

\section{Keywords}

Heart Rate Variability, Autonomic Nervous System, Stress, Age, Circadian Rhythm, Sleep

\section{Introduction}

Having breached the threshold of being a hyper-aging society, the prevalence of lifestyle-related diseases and soaring medical costs have emerged as issues of dire consequence in Japan. Modern-day society, in particular, is referred to as a 
"stress society" and according to statistics from the Health, Labour, and Welfare Ministry [1], nearly half of all people are living with some kind of stress as $46.5 \%$ of people reported experiencing worries or stress in their daily lives (Figure 1).

It is said that this kind of stress suffered by many Japanese people is closely related to autonomic nervous function [2]. Seen structurally and functionally, the autonomic nerves are positioned to connect the internal environment and the external environment, harmonize the functions of the body, regulate homeostasis (cardiovascular/respiratory control, body temperature regulation, gastrointestinal motility, urine/feces excretion function, reproductive function, metabolism/endocrine function), and perform adaptive response to stress ("fight or flight" reaction). Thus, the autonomic nervous system is doing what could be called indefatigable work in order to ensure the survival and proliferation of the species [3].

In 1921 Langley, a physiologist at the University of Cambridge, published "Autonomic Nervous System" and classified the autonomic nervous system into three systems: sympathetic nerves, parasympathetic nerves, and enteric nerves, establishing the current concept of autonomic nerves [3].

The sympathetic nerves together with parasympathetic nerves form the autonomic nervous system, and are the nerves that control the secretory glands, blood vessels, internal organs, and so on. During mental stimulation or exercise, they work to increase the activity of the whole body, such as secreting saliva, increasing blood pressure/blood sugar, constricting blood vessels in the skin and internal organs, and collecting blood in the muscles/brain [3].

On the other hand, the parasympathetic nerves emanate from the brain region and the sacral region and, mainly through the vagus nerve, secrete acetylcholine as a neurotransmitter. It acts to suppress the heart and excite the gastrointestinal tract. It also acts to promote bile secretion, promote secretion of tears and saliva, dilate the pupils, etc. These autonomic nervous functions are affected not only by physical stress but also by psychological stress [3].

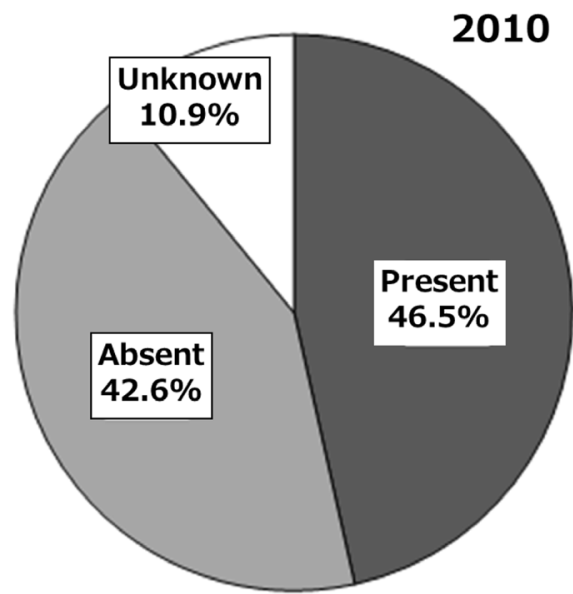

Note: Inpatients were not included.

Figure 1. Presence of worries or stress (age 12 and over). 
Traditionally, evaluation based on subjective values has been used as the means for quantifying stress. The Beck Depression Inventory (BDI) developed by Beck et al. [4] is a self-administered system of 21 question items that makes it possible to evaluate the severity of depression symptoms in the past two weeks. The adequate reliability and validity of the Japanese version of BDI have been confirmed by Sameshima et al. [5]. Developed by Zung [6], SDS (Self-rating Depression Scale) is a measure consisting of 20 items for evaluating emotional, physiological and psychological aspects of depression symptoms. The reliability and validity of the Japanese version of SDS have been confirmed by Fukuda et al. [7]. CES-D consists of 20 items, and is answered based on a 4-point scale [8]. The reliability and validity of the Japanese version of CES-D are being studied by Shima et al. [9].

Meanwhile, there are measurement methods using saliva, blood, and brain waves to evaluate stress based on objective values. Regarding saliva, it is possible to measure substances such as cortisol, which is an indicator of endocrine activity, SIgA, which is an indicator of immune activity, and $\alpha$-amylase, which is an indicator of sympathetic nerve activity, and all of these are known to reflect states of acute and chronic stress [10].

Regarding blood, it is said that cytokines are produced in the brain when under stress, and cytokines are produced from the immune cells in the blood through acceleration of the hypothalamus and autonomic nerves. There are reports that patients with depression have increased levels of such cytokines [11].

Regarding brain waves, the term alpha waves refers to the $8-13 \mathrm{~Hz}$ component of the electrical signal (brain waves) generated by the human or animal brain, and in the brain waves at the time of relaxation or when the eyes are closed, the proportion occupied by alpha waves is higher than that of other frequency components. They decrease when the eyes are open or during visual stimulation, physical exercise, or mental activity such as arithmetic memorization, or when nervous or asleep. At the present time, it has been found that alpha waves increase when relaxing [12].

However, these objective indices are, in the case of saliva measurement, time-consuming to collect and evaluate, and in the case of blood measurement, they are invasive, so there is a considerable physical burden on the test subject. Also, in the case of brain wave measurement, it is necessary to mount electrodes in multiple places, and it becomes a large-scale measurement. Therefore, it is difficult to evaluate stress easily using these methods, and they are not suitable for obtaining long-term data from a large number of test subjects.

Therefore, heart rate variability analysis can be included as a method for evaluating autonomic nervous function more simply and non-invasively. In recent years, it has become possible to measure the fluctuation of the heartbeat (interval between heartbeats) by using a small wearable heart rate sensor that can be worn in everyday life, and use heart rate variability analysis to calculate the indices of sympathetic nerve activity and parasympathetic nerve activity.

Generally, there is fluctuation of the heartbeat in a living body, and when this 
fluctuation is frequency analyzed, a peak can be seen at a certain frequency. In the case of a person, there appear a high frequency component $(0.15-0.40 \mathrm{~Hz}$ : $\mathrm{HF})$ reflecting the variation of the respiratory cycle and a low frequency component $(0.05-0.15 \mathrm{~Hz}$ : LF) reflecting fluctuation in blood pressure, both of which reflect autonomic nerve activity. It is said that HF is regulated by the parasympathetic nerves, and LF is regulated by both sympathetic and parasympathetic nerves [3].

There are several prior studies of the relationship between autonomic nervous indices and physiological phenomena that used such heart rate variability analysis.

Previous research has explored the relationship between the severity of depression based upon the SDS ("Self-rating Depression Scale") and autonomic activity obtained by analyzing heart rate variability from a Holter ECG monitor in 31 subjects (12 males and 19 females) diagnosed with mood disorders. In association with the severity of depression, the results demonstrated a significant rise in sympathetic nerve function along with significantly diminishing parasympathetic nerve function. Accordingly, in assessments of depression severity conducted with the use of Holter ECG monitors, these results support the onset of abnormalities in autonomic nerve function brought on by depression [13].

In another paper examining the effects of depression on the autonomic nervous system in 16 male subjects diagnosed with mild heart attacks, a trend was observed of elevated sympathetic nerve function and suppressed parasympathetic nerve function as subjects' scores rose on the SDS (denoting increasingly severe depression) [14]. Thus, abnormalities in autonomic nervous function wherein the sympathetic nerves are excited and the parasympathetic nerves are suppressed may conceivably have an effect on the pathogenesis and prognosis of heart attacks.

Also, in the Multiethnic Study of Atherosclerosis (MESA), a leading epidemiological study in the United States, as a result of investigating the relationship between depression symptoms, anger, anxiety, social support scores and parasympathetic nerve functions, evaluated in questionnaire form, it was observed that there was a significant negative association with symptoms of depression. Therefore, it is said that continuing depression in particular affects autonomic nervous function, especially parasympathetic function [15].

In addition to those people who have specific diseases as described above, there are several reports that the balance of the autonomic nervous system also changes with age. This is because the internal environment of the human body is kept constant by the homeostasis mechanism, but with age the balance of the autonomic nervous system deteriorates, so it is said to become difficult for the body to respond appropriately to changes in the external environment. In previous reports, a gradual decline in parasympathetic function due to aging in females and predominance of sympathetic function due to aging in males have been recognized, but many reports are based on the results of short-term measurement [16]. 
Consequently, in this study we used a small wearable heart rate sensor capable of long-term monitoring to test how age-related changes in levels of autonomic activity and diurnal variations in the autonomic nerves change as a function of age. We also attempt to reveal variations across age groups, diurnal variations, and variations between sleeping and waking states by monitoring a large pool of subjects ranging across all age groups as they went about their daily lives.

\section{Methodology}

In this study, we measured biological data from 600 subjects $(329$ males, $271 \mathrm{fe}-$ males) for a prolonged period of time (24 hours)using a small wearable heart rate sensor (WHS-1) produced by Union Tool Co., shown in Figure 2. Regarding the experiment, it was carried out after obtaining approval from the ethics committee of the medical institution and informed consent from the test subjects.

The small wearable heart rate sensor can measure RR intervals, body surface temperature, and triaxial acceleration. The sensor's sampling frequency for heart-rate intervals, body surface temperature, and triaxial acceleration is 1000 $\mathrm{Hz}, 1 \mathrm{~Hz}$, and $31.25 \mathrm{~Hz}$, respectively. Table 1 shows the distribution of gender and ages of the subjects.

Fast Fourier Transform (FFT) was used for the frequency analysis of the measured RR intervals, defining the low-frequency component (LF) as the

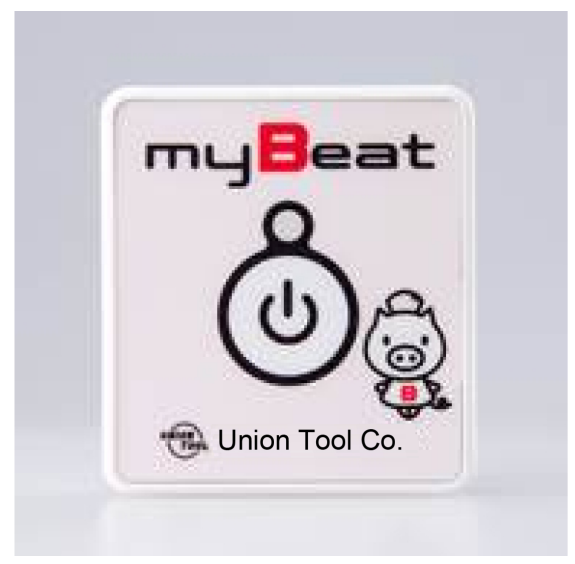

Figure 2. Small wearable heart rate sensor.

Table 1. Subjects' age and sex distribution.

\begin{tabular}{cccc}
\hline Age & Man & Female & Total \\
\hline 10 's & 26 & 23 & 49 \\
20 's & 59 & 39 & 98 \\
30 's & 95 & 47 & 142 \\
40 's & 77 & 87 & 164 \\
50 's & 37 & 44 & 81 \\
Over 60's & 35 & 31 & 66 \\
Total & 329 & 271 & 600 \\
\hline
\end{tabular}


frequencies between $0.04 \mathrm{~Hz}-0.15 \mathrm{~Hz}$ and the high-frequency component (HF) as the frequencies between $0.15 \mathrm{~Hz}-0.4 \mathrm{~Hz}$. The sum of the LF and HF components is referred to as total power (TP), and is considered to be an indicator of overall autonomic nervous activity. Our method for computing indicators of autonomic nerve activity adhered to procedures from paper [17] in the references. These indicators of autonomic nerve activity are also said to correlate with fatigue [18].

In this experiment, we use solely the data where subjects exhibit little body movement from among the long-term measurement data. To analyze the data, body movement levels were determined on the basis of the acceleration sensors embedded in the small wearable heart rate sensor using the supplied software (produced by WINFrontier Co.). It has been reported that, in general, the composite value of triaxial acceleration correlates to body activity indicators and energy consumption, and the values change while walking, running, and resting [19] [20] [21].

The threshold for the composite value of acceleration was configured in alignment with each of the activities (walking, running, resting) on the sensor to distinguish the activity. Only the data determined as being recorded at rest when there is little body movement was used. IBM SPSS Statistics Version 22 was used for statistical processing in this study, with the level of statistical significance being $5 \%$. We used the games-howell method for multiple comparison.

\section{The Relationship between Autonomic Nerve Function and Aging}

We investigated the relationship between age and the LF component of the autonomic nerve indicators. It is said that the LF component is a low frequency component $(0.05-0.15 \mathrm{~Hz})$ of heart rate variability analysis and is regulated by both sympathetic and parasympathetic nerves [3], but as it decreases with administration of $\beta$ blockers (propranolol: $0.15 \mathrm{mg} / \mathrm{kg}$ ), sympathetic nerves are said to be heavily involved [22].

Subjects were divided into six groups from teenagers to subjects aged 60-plus and the Games-Howell method was used to conduct multiple comparisons in order to examine the variances between groups. The results are shown in Figure 3 and Table 2. The results demonstrate a tendency for LF to peak in the 30's and trend downward thereafter.

Subsequently, the HF component was studied. Since the HF component is considered to be the high frequency component $(0.15-0.40 \mathrm{~Hz})$ of heart rate variability analysis and disappears with a parasympatholytic drug (atropine: 0.04 $\mathrm{mg} / \mathrm{kg}$ ), the cardiac vagus nerve is thought to be involved, and is said to display parasympathetic nervous activity [23].

The Games-Howell method was used to conduct multiple comparisons to examine the variances between the groups. The results are shown in Figure 4 and Table 3. The results indicate a tendency for HF to peak in the 20's and decline thereafter, reversing to an upward trend in the 60 's. 


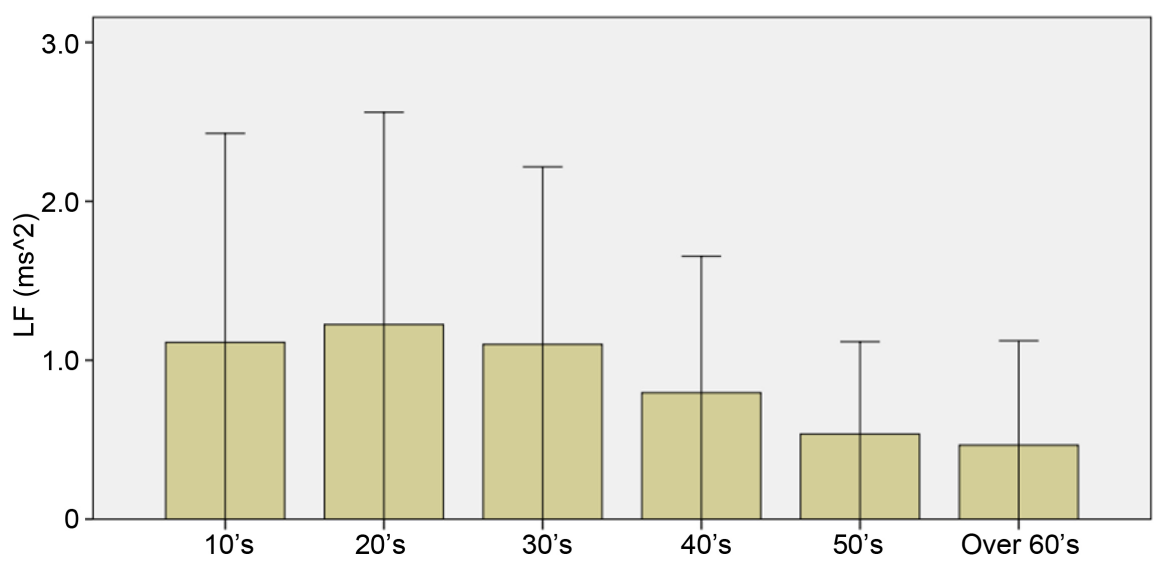

Figure 3. Relationship between LF and age.

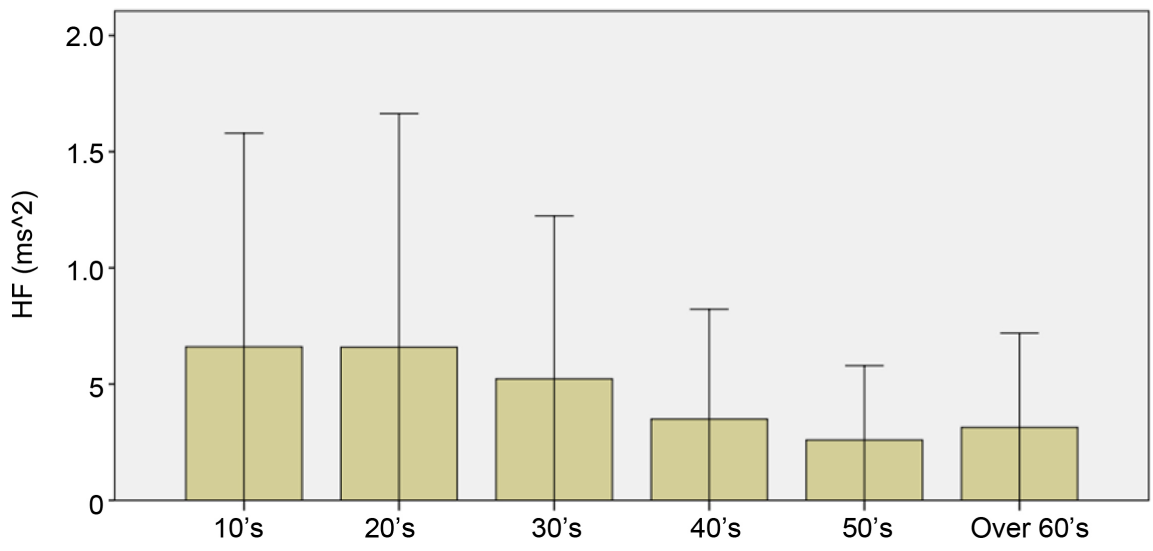

Figure 4. Relationship between HF and age.

Next, we investigated the relationship between total power (TP), an indicator of the autonomic nerves, and age. Total power is the sum of the LF and HF components and is considered to be an indicator representative of the volume of autonomic nerve activity [17]. Total power is said to be correlated with fatigue, and smaller values of total power are thought to indicate higher levels of fatigue accumulation [18].

The subjects were divided into six groups from teenagers to subjects aged 60-plus, and the Games-Howell method was used to conduct multiple comparisons in order to examine the variances between groups. The results are shown in Figure 5 and Table 4. The results indicate a tendency for TP to peak in the 20's with a declining trend thereafter.

Earlier studies also showed a tendency for LF, HF, and total power to decrease with aging [16] [24], and the same trend was observed in this study as well. In addition, it is possible that the trend of HF increasing in subjects in their sixties is influenced by the lifestyle changes that result from retirement, etc.

Finally, we examine the relationship between age and the LF/HF ratio, an indicator of the autonomic nerves. The LF/HF ratio is considered to be an indicator of the balance between the sympathetic and parasympathetic nerves, or an 
Table 2. Multiple comparisons (relationship between LF and age).

Dependent variable: $\mathrm{LF}\left(\mathrm{ms}^{2}\right)$

Games-Howell

\begin{tabular}{|c|c|c|c|c|c|c|}
\hline \multirow{2}{*}{ (I) Age flag } & \multirow{2}{*}{ (J) Age flag } & \multirow{2}{*}{ Mean difference (I-J) } & \multirow{2}{*}{ Std. error } & \multirow{2}{*}{ Sig. } & \multicolumn{2}{|c|}{ 95\% Confidence interval } \\
\hline & & & & & Lower bound & Upper bound \\
\hline \multirow[t]{5}{*}{10 's } & 20 's & $-0.112159369^{*}$ & 0.0140548007 & 0.000 & -0.152218228 & -0.072100510 \\
\hline & 30 's & 0.0120527425 & 0.0137553960 & 0.952 & -0.027153352 & 0.0512588369 \\
\hline & 40 's & $0.316947065^{*}$ & 0.136172453 & 0.000 & 0.2781344368 & 0.3557596934 \\
\hline & 50 ’s & $0.576613248^{*}$ & 0.0136477862 & 0.000 & 0.5377136369 & 0.6155128598 \\
\hline & Over 60’s & $0.646600454^{*}$ & 0.0138285632 & 0.000 & 0.6071859647 & 0.6860149426 \\
\hline \multirow[t]{5}{*}{20 's } & 10 's & $0.112159369^{*}$ & 0.0140548007 & 0.000 & 0.0721005100 & 0.1522182285 \\
\hline & 30 ’s & $0.124212112^{*}$ & 0.0050304089 & 0.000 & 0.4098767908 & 0.1385474326 \\
\hline & 40 's & $0.429106434^{*}$ & 0.0046393388 & 0.000 & 0.4158855298 & 0.4423273389 \\
\hline & 50 's & $0.688772618^{*}$ & 0.0047282304 & 0.000 & 0.6752983878 & 0.7022468475 \\
\hline & Over 60’s & $0.758772618^{*}$ & 0.0052271649 & 0.000 & 0.7438637352 & 0.7736559105 \\
\hline \multirow[t]{5}{*}{30 's } & 10 's & -0.01205742 & 0.0137553960 & 0.952 & -0.051258837 & 0.0271533519 \\
\hline & 20 's & $-0.124212112^{*}$ & 0.0050304089 & 0.000 & -0.138547433 & -0.109876791 \\
\hline & 40 's & $0.304894323^{*}$ & 0.0036327621 & 0.000 & 0.2945419477 & 0.3152466975 \\
\hline & 50 's & $0.564560506^{*}$ & 0.0037456186 & 0.000 & 0.55388647914 & 0.5452345204 \\
\hline & Over 60’s & $0.634547711^{*}$ & 0.0043585260 & 0.000 & 0.6221269835 & 0.6469684388 \\
\hline \multirow[t]{5}{*}{40 's } & 10 's & $-0.316947065^{*}$ & 0.0136172453 & 0.000 & -0.355759693 & -0.278134437 \\
\hline & 20 's & $-0.429106434^{*}$ & 0.0046393388 & 0.000 & -0.442327339 & -0.415885530 \\
\hline & 30 ’s & $-0.304894323^{*}$ & 0.0036327621 & 0.000 & -0.315246697 & -0.294541948 \\
\hline & 50 's & $0.259666193^{*}$ & 0.0032012668 & 0.000 & -0.2505434069 & 0.2687889597 \\
\hline & Over 60’s & 0.329653389 & 0.0039006665 & 0.000 & -0.3185373741 & 0.3107694029 \\
\hline \multirow[t]{5}{*}{50 's } & 10 's & $-0.546613248^{*}$ & 0.0136477862 & 0.000 & -0.614412860 & -0.537713637 \\
\hline & 20 's & $-0.688772618^{*}$ & 0.0047282304 & 0.000 & -0.702246847 & -0.575298388 \\
\hline & 30 's & $-0.564560506^{*}$ & 0.0037456186 & 0.000 & -0.575234520 & -0.553886491 \\
\hline & 40 ’s & $-0.259666183^{*}$ & 0.0032012668 & 0.000 & -0.268788960 & -0.250543407 \\
\hline & Over 60’s & $0.069987205^{*}$ & 0.0040059828 & 0.000 & 0.0585710597 & 0.0814033508 \\
\hline \multirow[t]{5}{*}{ Over 60’s } & 10 's & $-0.646600454^{*}$ & 0.0138285632 & 0.000 & -0.686014943 & -0.607185965 \\
\hline & 20 ’s & $-0.758459823^{*}$ & 0.0052271649 & 0.000 & -0.773655911 & -0.743863735 \\
\hline & 30 's & $-0.634547711^{*}$ & 0.0043585260 & 0.000 & -0.646968439 & -0.622126983 \\
\hline & 40 's & $-0.329653389^{*}$ & 0.0039006665 & 0.000 & -0.340769403 & -0.318537374 \\
\hline & 50 ’s & $-0.069987205^{*}$ & 0.0040059828 & 0.000 & -0.081403351 & -0.508571060 \\
\hline
\end{tabular}

${ }^{*}$ The mean difference is significant at the 0.05 level. 
Table 3. Multiple comparisons (relationship between HF and age).

\begin{tabular}{|c|c|c|c|c|c|c|}
\hline \multirow{2}{*}{ (I) Age flag } & \multirow{2}{*}{ (J) Age flag } & \multirow{2}{*}{$\begin{array}{c}\text { Mean } \\
\text { difference (I-J) }\end{array}$} & \multirow{2}{*}{ Std. error } & \multirow{2}{*}{ Sig. } & \multicolumn{2}{|c|}{ 95\% Confidence interval } \\
\hline & & & & & Lower bound & Upper bound \\
\hline \multirow[t]{5}{*}{10 's } & 20 's & 0.0012325036 & 0.0098947422 & 1.000 & -0.026969272 & 0.0294342789 \\
\hline & 30 's & $0.137519813^{\prime}$ & 0.0095776040 & 0.000 & 0.1102213130 & 0.1648183128 \\
\hline & 40 's & $0.310538135^{\star}$ & 0.0094768242 & 0.000 & 0.2835266626 & 0.3375496078 \\
\hline & 50 's & $0.400229014^{\star}$ & 0.0094902572 & 0.000 & 0.3731792839 & 0.4272787447 \\
\hline & Over 60's & $0.346629397^{\star}$ & 0.0096120152 & 0.000 & 0.3192328882 & 0.3740259052 \\
\hline \multirow[t]{5}{*}{20 's } & 10 's & -0.001232504 & 0.0098947422 & 1.000 & -0.029434279 & 0.0269692717 \\
\hline & 30 's & $0.136287309^{*}$ & 0.0035862520 & 0.000 & 0.1260674358 & 0.1465071828 \\
\hline & 40 's & $0.309305632^{\star}$ & 0.0033077032 & 0.000 & 0.2998795191 & 0.3187317442 \\
\hline & 50 ’s & $0.398996511^{*}$ & 0.0033459955 & 0.000 & 0.3894612762 & 0.4085317452 \\
\hline & Over 60’s & $0.345396893^{*}$ & 0.0036771648 & 0.000 & 0.3349179180 & 0.3558758682 \\
\hline \multirow[t]{5}{*}{30 's } & 10 's & $-0.137519813^{\prime \prime}$ & 0.0095776040 & 0.000 & -0.164818313 & -0.110221313 \\
\hline & 20 's & $-0.136287309^{\prime}$ & 0.0035862520 & 0.000 & -0.146507183 & -0.126067436 \\
\hline & 40 's & $0.173018322^{\star}$ & 0.0021829970 & 0.000 & 0.1667973767 & 0.1792392680 \\
\hline & 50 's & $0.262709201^{\star}$ & 0.0022405938 & 0.000 & 0.2563241089 & 0.2690942939 \\
\hline & Over 60’s & $0.209109584^{*}$ & 0.0027103720 & 0.000 & 0.2013856925 & 0.2168334751 \\
\hline \multirow[t]{5}{*}{40 's } & 10 's & $-0.310538135^{\prime}$ & 0.0094768242 & 0.000 & -0.337549608 & -0.283526663 \\
\hline & 20 's & $-0.309305632^{*}$ & 0.0033077032 & 0.000 & -0.318731744 & -0.299879519 \\
\hline & 30 's & $-0.173018322^{\star}$ & 0.0021829970 & 0.000 & -0.179239268 & -0.166797377 \\
\hline & 50 's & $0.089690879^{*}$ & 0.0017606697 & 0.000 & 0.0846734292 & 0.0947083290 \\
\hline & Over 60's & $0.036091261^{\prime}$ & 0.0023293375 & 0.000 & 0.0294531592 & 0.0427293637 \\
\hline \multirow[t]{5}{*}{50 's } & 10 's & $-0.400229014^{\prime}$ & 0.0094902572 & 0.000 & -0.427278745 & -0.373179284 \\
\hline & 20 's & $-0.398996511^{\prime}$ & 0.0033459955 & 0.000 & -0.408531745 & -0.389461276 \\
\hline & 30 's & $-0.262709201^{\prime}$ & 0.0022405938 & 0.000 & -0.269094294 & -0.256324109 \\
\hline & 40 's & -0.089690879 & 0.0017606697 & 0.000 & -0.094708329 & -0.084673429 \\
\hline & Over 60's & $-0.053599618^{\prime}$ & 0.0023834006 & 0.000 & -0.060391786 & -0.046807450 \\
\hline \multirow[t]{5}{*}{ Over 60’s } & 10 's & $-0.346629397^{\star}$ & 0.0096120152 & 0.000 & -0.374025905 & -0.319232888 \\
\hline & 20 's & $-0.345396893^{*}$ & 0.0036771648 & 0.000 & -0.355875868 & -0.334917918 \\
\hline & 30 's & $-0.209109584^{*}$ & 0.0027103720 & 0.000 & -0.216833475 & -0.201385692 \\
\hline & 40 's & $-0.036091261^{\prime}$ & 0.0023293375 & 0.000 & -0.042729364 & -0.029453159 \\
\hline & 50 's & $0.053599618^{\prime}$ & 0.0023834006 & 0.000 & 0.0468074498 & 0.0603917855 \\
\hline
\end{tabular}

${ }^{*}$ The mean difference is significant at the 0.05 level.

indicator of sympathetic nerve activity, although as mentioned earlier, interpretations are split. The subjects were divided into six groups from teenagers to subjects aged 60-plus, and the Games-Howell method was used to conduct multiple comparisons in order to examine the variances between groups. The results are shown in Figure 6 and Table 5. The results indicate a tendency for the 


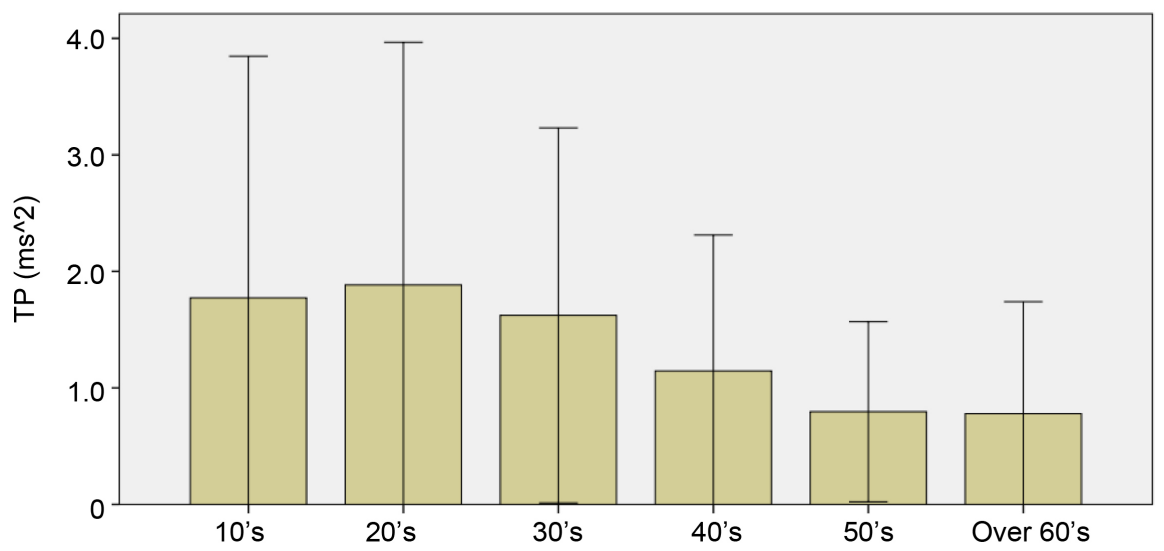

Figure 5. Relationship between TP and age.

Table 4. Multiple comparisons (relationship between TP and age).

\begin{tabular}{|c|c|c|c|c|c|c|}
\hline \multicolumn{7}{|c|}{$\begin{array}{l}\text { Multiple comparisons } \\
\text { Dependent variable: TP } \\
\text { Games-Howell }\end{array}$} \\
\hline \multirow[b]{2}{*}{ (I) Age flag } & \multirow[b]{2}{*}{ (j) Age flag } & \multirow{2}{*}{$\begin{array}{c}\text { Mean } \\
\text { difference (I-J) }\end{array}$} & \multirow[b]{2}{*}{ Std. error } & \multirow[b]{2}{*}{ Sig. } & \multicolumn{2}{|c|}{ 95\% Confidence interval } \\
\hline & & & & & Lower bound & Upper bound \\
\hline \multirow[t]{5}{*}{10 's } & 20 's & $-0.110926866^{*}$ & 0.0221587508 & 0.000 & -0.174083568 & -0.047770163 \\
\hline & 30 's & $0.149572555^{\star}$ & 0.0216270603 & 0.000 & 0.0879302055 & 0.2112149052 \\
\hline & 40 's & $0.627485200^{*}$ & 0.0214196776 & 0.000 & 0.5664334909 & 0.6885369097 \\
\hline & 50 's & $0.976842263^{\star}$ & 0.0214451137 & 0.000 & 0.9157181096 & 1.037966416 \\
\hline & Over 60’s & $0.993229850^{*}$ & 0.0217387010 & 0.000 & 0.9312695297 & 1.055190171 \\
\hline \multirow[t]{5}{*}{20 's } & 10 's & $0.110926866^{\star}$ & 0.0221587508 & 0.000 & 0.0477701630 & 0.1740835683 \\
\hline & 30 ’s & $0.260499421^{\star}$ & 0.0076507554 & 0.000 & 0.2386968006 & 0.2823020414 \\
\hline & 40 's & $0.738412066^{\prime}$ & 0.0070432171 & 0.000 & 0.7183407143 & 0.7584834177 \\
\hline & 50 's & $1.08776913^{*}$ & 0.0071201982 & 0.000 & 1.067478395 & 1.108059862 \\
\hline & Over 60’s & $1.10415672^{\star}$ & 0.0079608695 & 0.000 & 1.081470275 & 1.126843157 \\
\hline \multirow[t]{5}{*}{30 's } & 10 's & $-0.149572555^{\star}$ & 0.0216270603 & 0.000 & -0.211214905 & -0.087930206 \\
\hline & 20 's & $-0.260499421^{\star}$ & 0.0076507554 & 0.000 & -0.282302041 & -0.238696801 \\
\hline & 40 's & $0.477912645^{\star}$ & 0.0051309270 & 0.000 & 0.4632909081 & 0.4925343818 \\
\hline & 50 's & $0.827269707^{\star}$ & 0.0052360984 & 0.000 & 0.8123482271 & 0.8421911876 \\
\hline & Over 60's & $0.843657295^{\prime}$ & 0.0063320570 & 0.000 & 0.8256124836 & 0.8617021062 \\
\hline \multirow[t]{5}{*}{40 's } & 10 's & $-0.627485200^{*}$ & 0.0214196776 & 0.000 & -0.688536910 & -0.566433491 \\
\hline & 20 's & $-0.738412066^{\star}$ & 0.0070432171 & 0.000 & -0.758483418 & -0.718340714 \\
\hline & 30 's & $-0.477912645^{\star}$ & 0.0051309270 & 0.000 & -0.492534382 & -0.463290908 \\
\hline & 50 's & $0.34935706^{*}$ & 0.0042999506 & 0.000 & 0.3371033265 & 0.3616107982 \\
\hline & Over 60’s & $0.365744650^{*}$ & 0.0055828125 & 0.000 & 0.3498348727 & 0.3816544272 \\
\hline \multirow[t]{5}{*}{50 's } & 10 's & $-0.976842263^{\star}$ & 0.0214451137 & 0.000 & -1.03796642 & -0.915718110 \\
\hline & 20 's & $-1.08776913^{\star}$ & 0.0071201982 & 0.000 & -1.10805986 & -1.06747839 \\
\hline & 30 's & $-0.827269707^{\star}$ & 0.0052360984 & 0.000 & -0.842191188 & -0.812348227 \\
\hline & 40 's & $-0.349357062^{\star}$ & 0.0042999506 & 0.000 & -0.361610798 & -0.337103327 \\
\hline & Over 60’s & $0.016387588^{\star}$ & 0.0056796224 & 0.045 & 0.0002019182 & 0.0325732570 \\
\hline \multirow[t]{5}{*}{ Over 60’s } & 10 's & $-0.993229850^{*}$ & 0.0217387010 & 0.000 & -1.05519017 & -0.931269530 \\
\hline & 20 's & $-1.10415672^{\star}$ & 0.0079608695 & 0.000 & -1.12684316 & -1.08147028 \\
\hline & 30 's & $-0.843657295^{\star}$ & 0.0063320570 & 0.000 & -0.861702106 & -0.825612484 \\
\hline & 40 's & $-0.365744650^{\star}$ & 0.0055828125 & 0.000 & -0.381654427 & -0.349834873 \\
\hline & 50 's & $-0.016387588^{*}$ & 0.0056796224 & 0.045 & -0.032573257 & -0.000201918 \\
\hline
\end{tabular}

*The mean difference is significant at the 0.05 level. 


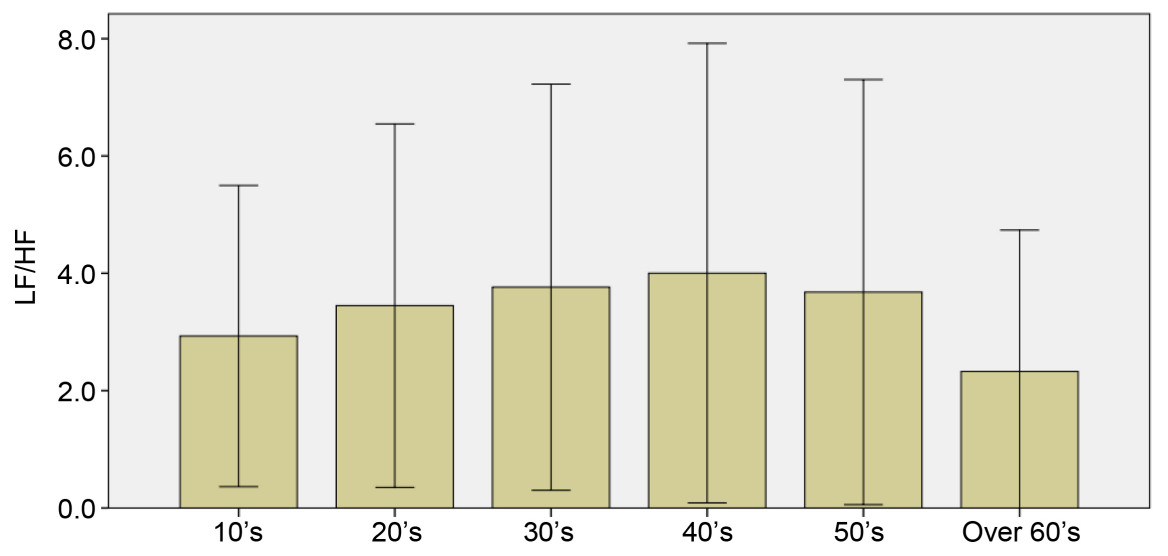

Figure 6. Relationship between LF/HF and age.

Table 5. Multiple comparisons (relationship between LF/HF and age).

\begin{tabular}{|c|c|c|c|c|c|c|}
\hline \multicolumn{7}{|c|}{$\begin{array}{l}\text { Multiple comparisons } \\
\text { Dependent variable: LF/HF } \\
\text { Games-Howell }\end{array}$} \\
\hline \multirow[b]{2}{*}{ (I) Age flag } & \multirow[b]{2}{*}{ (J) Age flag } & \multirow{2}{*}{$\begin{array}{c}\text { Mean } \\
\text { difference (I-J) }\end{array}$} & \multirow[b]{2}{*}{ Std. error } & \multirow[b]{2}{*}{ Sig. } & \multicolumn{2}{|c|}{ 95\% Confidence interval } \\
\hline & & & & & Lower bound & Upper bound \\
\hline \multirow[t]{5}{*}{10 's } & 20 ’s & $-0.518237016^{*}$ & 0.0279154228 & 0.000 & -0.597800398 & -0.438673634 \\
\hline & 30 ’s & $-0.832669919^{\star}$ & 0.0277558174 & 0.000 & -0.911778684 & -0.753561154 \\
\hline & 40 ’s & $-1.07084570^{*}$ & 0.0280485861 & 0.000 & -1.15078837 & -0.990903024 \\
\hline & 50 ’s & $-0.747990162^{\star}$ & 0.0300676722 & 0.000 & -0.833684432 & -0.662295891 \\
\hline & Over 60’s & $0.604431896^{*}$ & 0.0288130236 & 0.000 & 0.5223116679 & 0.6865521250 \\
\hline \multirow[t]{5}{*}{20 's } & 10 ’s & $0.518237016^{*}$ & 0.0279154228 & 0.000 & 0.4386736344 & 0.5978003984 \\
\hline & 30 ’s & $-0.314432902^{\star}$ & 0.0131144537 & 0.000 & -0.351805533 & -0.277060272 \\
\hline & 40 's &,$- 552608683^{*}$ & 0.0137232167 & 0.000 & -0.591716104 & -0.513501262 \\
\hline & 50 ’s & $-0.229753145^{\star}$ & 0.0174833751 & 0.000 & -0.279576482 & -0.179929809 \\
\hline & Over 60’s & $1.12266891^{\star}$ & 0.0152247767 & 0.000 & 1.079281900 & 1.166055925 \\
\hline \multirow[t]{5}{*}{30 ’s } & 10 's & $0.832669919^{*}$ & 0.0277558174 & 0.000 & 0.7535611539 & 0.9117786837 \\
\hline & 20 ’s & $0.314432902^{*}$ & 0.0131144537 & 0.000 & 0.2770602722 & 0.3518055326 \\
\hline & 40 's & $-0.238175780^{*}$ & 0.0133955682 & 0.000 & -0.276349449 & -0.200002112 \\
\hline & 50 's & $0.084679757^{*}$ & 0.0172273902 & 0.000 & 0.0355858975 & 0.1337736169 \\
\hline & Over 60’s & $1.43710182^{*}$ & 0.0149301170 & 0.000 & 1.394554496 & 1.479649135 \\
\hline \multirow[t]{5}{*}{40 's } & 10 's & $1.07084570^{*}$ & 0.0280485861 & 0.000 & 0.9909030245 & 1.150788374 \\
\hline & 20 's & $0.552608683^{*}$ & 0.0137232167 & 0.000 & 0.5135012615 & 0.5917161041 \\
\hline & 30 's & $0.238175780^{*}$ & 0.0133955682 & 0.000 & 0.2000021120 & 0.2763494489 \\
\hline & 50 's & $0.322855538^{*}$ & 0.0176952184 & 0.000 & 0.2724285569 & 0.3732825184 \\
\hline & Over 60’s & $1.67527760^{\star}$ & 0.0154675847 & 0.000 & 1.631198717 & 1.719356475 \\
\hline \multirow[t]{5}{*}{50 's } & 10 's & $0.747990162^{\star}$ & 0.0300676722 & 0.000 & 0.6622958908 & 0.8336844324 \\
\hline & 20 's & $0.229753145^{\star}$ & 0.0174833751 & 0.000 & 0.1799298088 & 0.2795764816 \\
\hline & 30 's &,$- 084679757^{*}$ & 0.0172273902 & 0.000 & -0.133773617 & -0.035585897 \\
\hline & 40 's & $-0.322855538^{\star}$ & 0.0176952184 & 0.000 & -0.373282518 & -0.272428557 \\
\hline & Over 60’s & $1.35242206^{*}$ & 0.0188835352 & 0.000 & 1.298608520 & 1.406235596 \\
\hline \multirow[t]{5}{*}{ Over 60’s } & 10 's & $-0.604431896^{*}$ & 0.0288130236 & 0.000 & -00.686552125 & -0.522311668 \\
\hline & 20 's & $-1.12266891^{\star}$ & 0.0152247767 & 0.000 & -1.16605593 & -1.07928190 \\
\hline & 30 's & $-1.43710182^{\star}$ & 0.0149301170 & 0.000 & -1.47964913 & -1.39455450 \\
\hline & 40 's & $-1.67527760^{*}$ & 0.0154675847 & 0.000 & -1.71935647 & -1.63119872 \\
\hline & 50 's & $-1.35242206^{*}$ & 0.0188835352 & 0.000 & -1.40623560 & -1.29860852 \\
\hline
\end{tabular}

${ }^{\star}$ The mean difference is significant at the 0.05 level. 
$\mathrm{LF} / \mathrm{HF}$ ratio to peak in the 40 s and trend downward thereafter.

In previous studies by Zhang et al. [24], there was a tendency for this LF/HF decrease from a peak in the subject's 50's, which is about 10 years different from this study, but the tendency for stress to decrease with is consistent.

In addition, looking at the Ministry of Health, Labor and Welfare statistics shown in Figure 7 [1], there is a tendency for the proportion of anxiety and stress in everyday life to decrease from a peak in the subject's 40 's, and it is consistent with the LF/HF changes with age of this study.

Also, in the Ministry of Health, Labor and Welfare statistics shown in Figure 8 [1], there are two anxieties that increase in those in their 50's and above-"my illness and nursing care" and "family illness and nursing care"-and the trend is for other anxieties to decrease. Thus, the number of anxieties for people in their 50 's and above is reduced compared with the younger generation, they are mentally mature, and can be considered possible that by acquiring methods to cope with stress they have a higher stress tolerance.

\section{The Relationship between Autonomic Nervous Function and Circadian Rhythm/Sleep}

In this section, we analyzed the relationship between the autonomic nerve indicator LF/HF ratio and diurnal variations in order to assess the relationship between autonomic nerve function and diurnal variations. The analysis divided one day into eight three-hour sections. Figure 9, Table 6, and Table 7 show the aggregate results for subjects under the age of 50. Figure 10, Table 8 , and Table 9

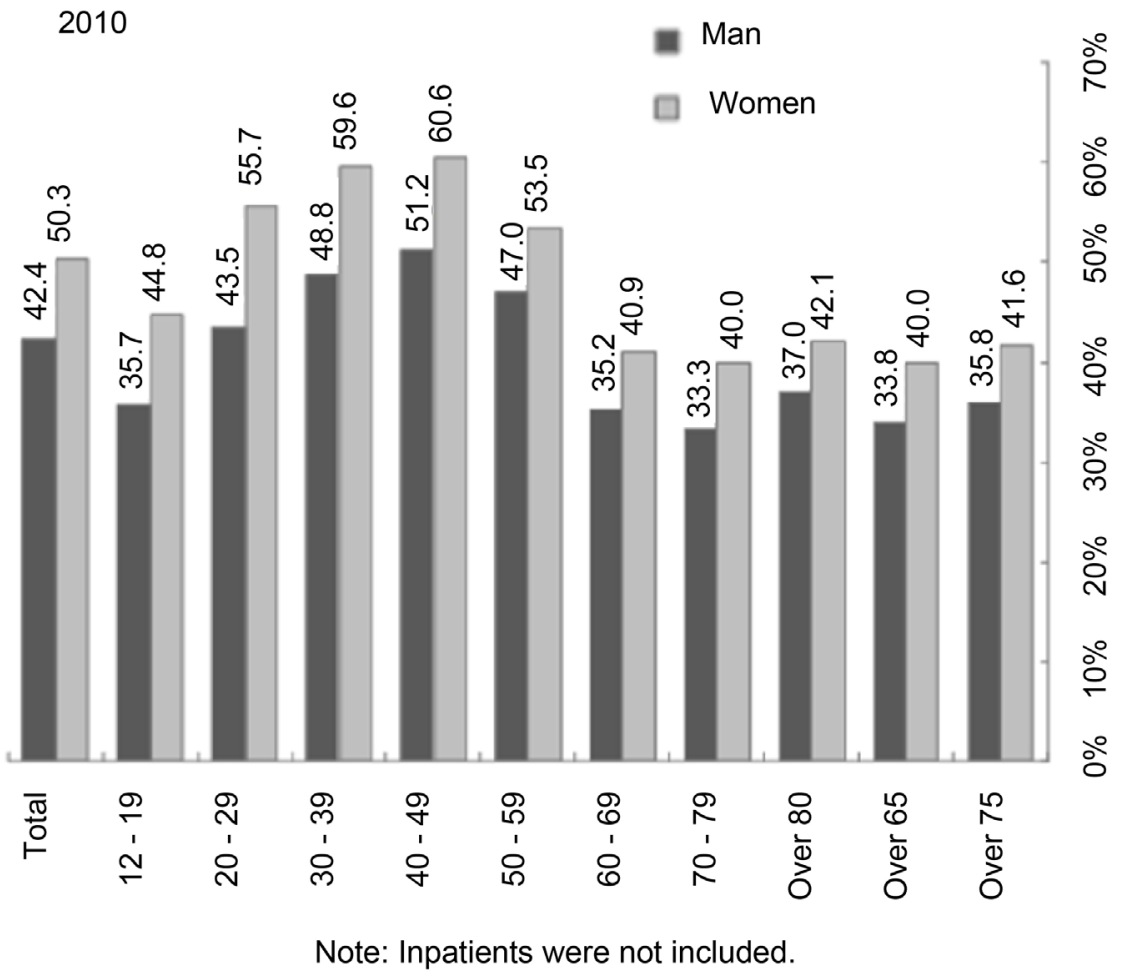

Figure 7. Presence of worries or stress by age and sex (age 12 and over). 


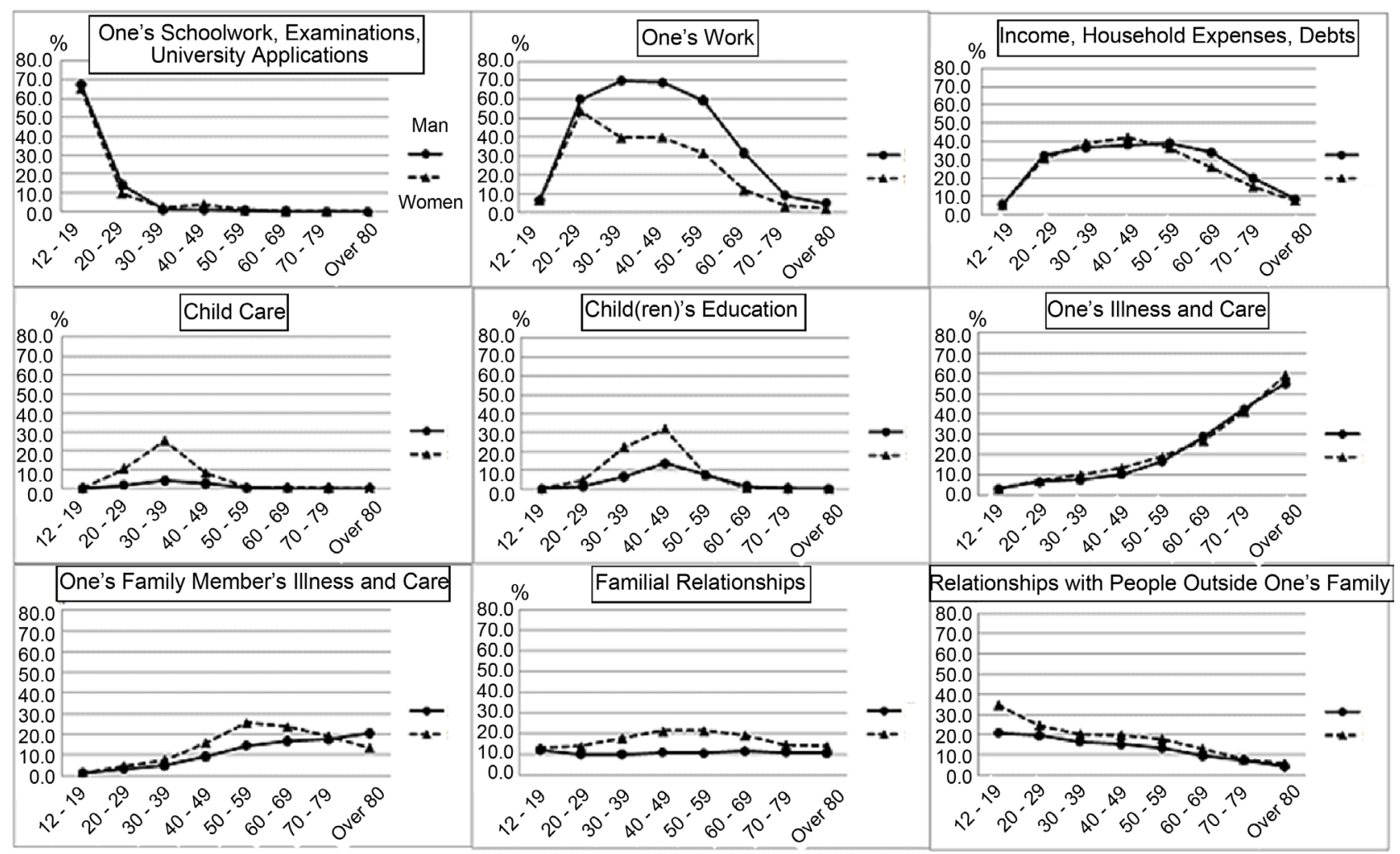

Figure 8. Primary cause of worries or stress by age and sex (age 12 and over).

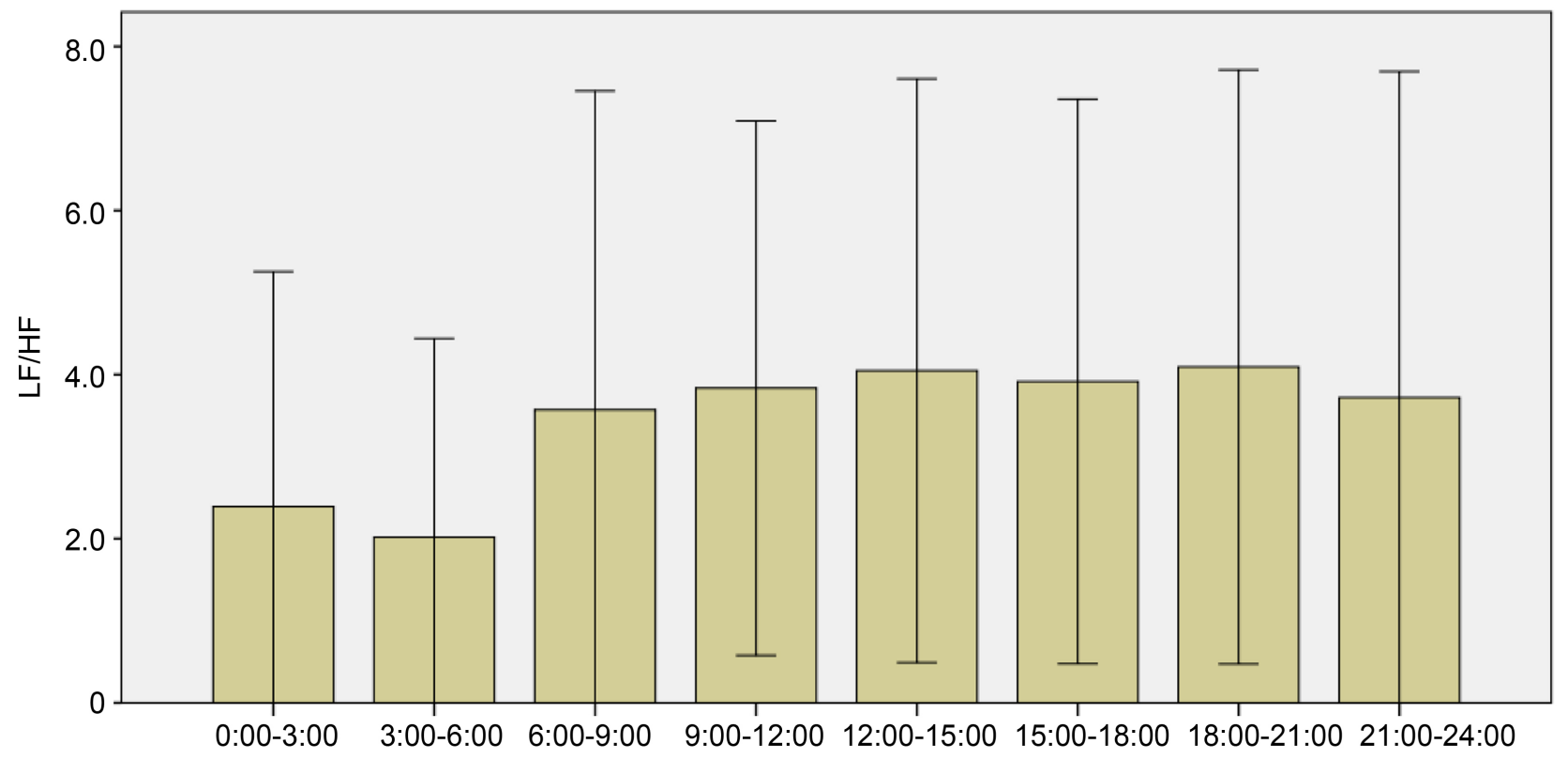

Figure 9. Relationship between LF/HF and circadian rhythm in subjects under 50 years of age.

show the aggregate results for subjects aged 50-plus.

Comparing the diurnal variations of the LF/HF ratio for subjects below 50 against subjects aged 50-plus reveals striking differences in the elevation rates of the LF/HF ratio from between 3:00 and 6:00 in the morning to between 6:00 and 9:00 in the morning. 
Table 6. Relationship between LF/HF and circadian rhythm in subjects under 50 years of age (descriptive statistics).

\begin{tabular}{|c|c|c|c|c|c|c|c|c|}
\hline \multicolumn{9}{|c|}{$\begin{array}{c}\text { Descriptives } \\
\text { LFHF }\end{array}$} \\
\hline & \multirow{2}{*}{$\mathrm{N}$} & \multirow{2}{*}{ Mean } & \multirow{2}{*}{ Std. deviation } & \multirow{2}{*}{ Std. error } & \multicolumn{2}{|c|}{$95 \%$ Confidence interval for mean } & \multirow{2}{*}{ Minimum } & \multirow{2}{*}{ Maximum } \\
\hline & & & & & Lower bound & upper bound & & \\
\hline 0:00-3:00 & 67,836 & 2.393469930 & 2.863404234 & 0.0109939194 & 2.371921866 & 2.415017993 & 0.0207066132 & 50.54979966 \\
\hline $3: 00-6: 00$ & 64,337 & 2.020522403 & 2.419858802 & 0.0095402471 & 2.001823516 & 2.039221289 & 0.0310185554 & 71.04799683 \\
\hline $6: 00-9: 00$ & 59,273 & 3.573768236 & 3.883893100 & 0.0159528695 & 3.542500558 & 3.605035915 & 0.0536916576 & 69.86762657 \\
\hline $9: 00-12: 00$ & 75,585 & 3.835712749 & 3.256889566 & 0.0118463681 & 3.812493930 & 3.858931568 & 0.0150149330 & 56.80034183 \\
\hline $12: 00-15: 00$ & 74,545 & 4.048507535 & 3.558050522 & 0.0130317533 & 4.022965361 & 4.074049709 & 0.0806316874 & 60.71608144 \\
\hline $15: 00-18: 00$ & 75,799 & 3.916584321 & 3.440740240 & 0.0124974138 & 3.892089457 & 3.941079185 & 0.0541924435 & 60.96557143 \\
\hline $18: 00-21: 00$ & 68,882 & 4.094753570 & 3.621127728 & 0.0137972003 & 4.067711088 & 4.121796053 & 0.0466757865 & 58.15724576 \\
\hline $21: 00-24: 00$ & 63,486 & 3.720298319 & 3.975522798 & 0.0157781204 & 3.689373191 & 3.751223446 & 0.0382549455 & 124.3444459 \\
\hline Total & 549,743 & 3.476204212 & 3.483718151 & 0.0046985425 & 3.466995221 & 3.485413204 & 0.0150149330 & 124.3444459 \\
\hline
\end{tabular}

Looking at the standard deviation of the average value of LF/HF in each time period, it is 0.739 for those under 50 years old, but it is 0.419 for those 50 years old and above, and the trend is for the fluctuation of autonomic nervous function to decrease in the elderly.

Sympathetic nerve activity should become vigorous in the morning in preparation for activity during the day because of human circadian rhythms; however, this switch is faint for subjects aged 50 and up. In other words, this may indicate the possibility of a decline in responsiveness of the autonomic nerves and a drop off in adaptability to the external environment.

There are several previous studies on the decline in responsiveness of the autonomic nervous system with aging, and when healthy people of different generations were examined using the orthostatic hypotension test, the deep breath test, and the perspiration reaction, the average reaction amount statistically significantly decreased as the age group increased, and the response of the autonomic nerves to changes in the environmental or the body tended to be slower [25]. Shimazu et al. also report increased sympathetic function and decreased responsiveness of the autonomic nervous system associated with aging [26].

Thus, the tendency of LF/HF in this study appears the same as the trend for autonomic nerves to change with age seen in previous studies, and a tendency was seen that suggests a decrease in responsiveness with aging.

Next, we analyzed the relationship between the autonomic nerve indicator LF/HF ratio while sleeping and waking.

Figure 11, Table 10, and Table 11 show a comparison of the LF/HF ratio while sleeping and waking for subjects under the age of 50 .

Figure 12, Table 12 and Table 13 show a comparison of the LF/HF ratio while sleeping and waking for subjects aged 50-plus.

Comparing the variations while sleeping and waking of the LF/HF ratio for subjects under 50 and subjects aged 50 and up, although both groups exhibit significant differences while sleeping and while waking, the variations between 
Table 7. Relationship between LF/HF and circadian rhythm in subjects under 50 years of age (multiple comparisons).

\begin{tabular}{|c|c|c|c|c|c|c|}
\hline \multicolumn{7}{|c|}{$\begin{array}{l}\text { Multiple comparisons } \\
\text { Dependent variable: LFHF } \\
\text { Games-Howell }\end{array}$} \\
\hline \multirow[b]{2}{*}{ (I) Time flag } & \multirow[b]{2}{*}{ (J) Time flag } & Mean & \multirow[b]{2}{*}{ Std. error } & \multirow[b]{2}{*}{ Sig. } & \multicolumn{2}{|c|}{ 95\% Confidence interval } \\
\hline & & Difference (I-J) & & & $\begin{array}{l}\text { Lower } \\
\text { bound }\end{array}$ & $\begin{array}{l}\text { Upper } \\
\text { bound }\end{array}$ \\
\hline \multirow[t]{7}{*}{ 0:00-3:00 } & 3:00-6:00 & $0.372947527^{\star}$ & 0.0145562 & 0 & 0.3288288 & 0.4170663 \\
\hline & $6: 00-9: 00$ & $-1.18029831^{*}$ & 0.0193742 & 0 & -1.2390204 & -1.1215763 \\
\hline & 9:00-12:00 & $-1.44224282^{*}$ & 0.0161618 & 0 & -1.4912279 & -1.3932577 \\
\hline & $12: 00-15: 00$ & $-1.65503761^{*}$ & 0.0170497 & 0 & -1.706714 & -1.6033612 \\
\hline & $15: 00-18: 00$ & $-1.52311439^{*}$ & 0.0166449 & 0 & -1.5735637 & -1.4726651 \\
\hline & $18: 00-21: 00$ & $-1.70128364^{\star}$ & 0.0176417 & 0 & -1.7547543 & -1.647813 \\
\hline & 21:00-24:00 & $-1.32682839^{\star}$ & 0.0192306 & 0 & -1.385115 & -1.2685418 \\
\hline \multirow[t]{7}{*}{$3: 00-6: 00$} & 0:00-3:00 & $-0.372947527^{*}$ & 0.0145562 & 0 & -0.4170663 & -0.3288288 \\
\hline & 6:00-9:00 & $-1.55324583^{*}$ & 0.0185879 & 0 & -1.6095848 & -1.4969069 \\
\hline & 9:00-12:00 & $-1.81519035^{\star}$ & 0.0152103 & 0 & -1.8612916 & -1.7690891 \\
\hline & $12: 00-15: 00$ & $-2.02798513^{*}$ & 0.0161506 & 0 & -2.0769365 & -1.9790337 \\
\hline & $15: 00-18: 00$ & $-1.89606192^{\star}$ & 0.0157226 & 0 & -1.9437161 & -1.8484077 \\
\hline & $18: 00-21: 00$ & -2.0742311 & 0.0167744 & 0 & -2.1250731 & -2.0233892 \\
\hline & $21: 00-24: 00$ & $-1.69977592^{\star}$ & 0.0184382 & 0 & -1.7556609 & -1.643891 \\
\hline \multirow[t]{7}{*}{ 6:00-9:00 } & 0:00-3:00 & $1.18029831^{\star}$ & 0.0193742 & 0 & 1.1215762 & 1.2390204 \\
\hline & $3: 00-6: 00$ & $1.55324583^{*}$ & 0.0185879 & 0 & 1.4969069 & 1.6095848 \\
\hline & $9: 00-12: 00$ & $-0.261944513^{*}$ & 0.0198703 & 0 & -0.3221702 & -0.2017188 \\
\hline & $12: 00-15: 00$ & $-0.474739299^{*}$ & 0.020599 & 0 & -0.5371736 & -0.412305 \\
\hline & 15:00-18:00 & $-0.342816085^{\star}$ & 0.0202652 & 0 & -0.4042386 & -0.2813936 \\
\hline & $18: 00-21: 00$ & $-0.520985334^{*}$ & 0.0210916 & 0 & -0.5849126 & -0.4570581 \\
\hline & $21: 00-24: 00$ & $-0.146530082^{*}$ & 0.0224375 & 0 & -0.2145367 & -0.0785234 \\
\hline \multirow[t]{7}{*}{$9: 00-12: 00$} & 0:00-3:00 & $1.44224282^{*}$ & 0.0161618 & 0 & 1.3932577 & 1.4912279 \\
\hline & $3: 00-6: 00$ & $1.81519035^{\star}$ & 0.0152103 & 0 & 1.7690891 & 1.8612916 \\
\hline & 6:00-9:00 & $0.261944513^{\star}$ & 0.0198703 & 0 & 0.2017188 & 0.3221702 \\
\hline & $12: 00-15: 00$ & $-0.212794786^{*}$ & 0.0176114 & 0 & -0.2661737 & -0.1594159 \\
\hline & 15:00-18:00 & $-0.080871572^{\star}$ & 0.0172198 & 0 & -0.1330635 & -0.0286797 \\
\hline & $18: 00-21: 00$ & $-0.259040821^{*}$ & 0.0181851 & 0 & -0.3141586 & -0.203923 \\
\hline & 21:00-24:00 & $0.115414430^{\prime}$ & 0.0197303 & 0 & 0.0556132 & 0.1752157 \\
\hline \multirow[t]{7}{*}{$12: 00-15: 00$} & 0:00-3:00 & $1.65503761^{*}$ & 0.0170497 & 0 & 1.6033612 & 1.706714 \\
\hline & $3: 00-6: 00$ & $2.02798513^{*}$ & 0.0161506 & 0 & 1.9790337 & 2.0769365 \\
\hline & $6: 00-9: 00$ & $0.474739299^{*}$ & 0.020599 & 0 & 0.412305 & 0.5371736 \\
\hline & $9: 00-12: 00$ & $0.212794786^{\prime}$ & 0.0176114 & 0 & 0.1594159 & 0.2661737 \\
\hline & $15: 00-18: 00$ & $0.131923214^{*}$ & 0.0180558 & 0 & 0.0771975 & 0.1866489 \\
\hline & $18: 00-21: 00$ & -0.046246 & 0.0189787 & 0.224 & -0.1037689 & 0.0112768 \\
\hline & 21:00-24:00 & $0.328209216^{*}$ & 0.020464 & 0 & 0.2661843 & 0.3902342 \\
\hline 15:00-18:00 & 0:00-3:00 & $1.52311439^{*}$ & 0.0166449 & 0 & 1.4726651 & 1.5735637 \\
\hline
\end{tabular}




\section{Continued}

\begin{tabular}{|c|c|c|c|c|c|c|}
\hline & $3: 00-6: 00$ & $1.89606192^{\star}$ & 0.0157226 & 0 & 1.8484077 & 1.9437161 \\
\hline & $6: 00-9: 00$ & $0.342816085^{\star}$ & 0.0202652 & 0 & 0.2813936 & 0.4042386 \\
\hline & 9:00-12:00 & $0.080871572^{\star}$ & 0.0172198 & 0 & 0.0286797 & 0.1330635 \\
\hline & $12: 00-15: 00$ & $-0.131923214^{*}$ & 0.0180558 & 0 & -0.1866489 & -0.0771975 \\
\hline & $18: 00-21: 00$ & $-0.178169249^{*}$ & 0.0186158 & 0 & -0.2345923 & -0.1217462 \\
\hline & $21: 00-24: 00$ & $0.196286002^{\star}$ & 0.020128 & 0 & 0.1352796 & 0.2572924 \\
\hline \multirow[t]{7}{*}{$18: 00-21: 00$} & 0:00-3:00 & $1.70128364^{\star}$ & 0.0176417 & 0 & 1.647813 & 1.7547543 \\
\hline & $3: 00-6: 00$ & $2.07423117^{\star}$ & 0.0167744 & 0 & 2.0233892 & 2.1250731 \\
\hline & $6: 00-9: 00$ & $0.520985334^{\star}$ & 0.0210916 & 0 & 0.4570581 & 0.5849126 \\
\hline & 9:00-12:00 & $0.259040821^{\star}$ & 0.0181851 & 0 & 0.203923 & 0.3141586 \\
\hline & $12: 00-15: 00$ & 0.046246 & 0.0189787 & 0.224 & -0.0112768 & 0.1037689 \\
\hline & 15:00-18:00 & $0.178169249^{*}$ & 0.0186158 & 0 & 0.1217462 & 0.2345923 \\
\hline & 21:00-24:00 & $0.374455252^{*}$ & 0.0209598 & 0 & 0.3109277 & 0.4379828 \\
\hline \multirow[t]{7}{*}{$21: 00-24: 00$} & 0:00-3:00 & $1.32682839^{*}$ & 0.0192306 & 0 & 1.2685417 & 1.385115 \\
\hline & $3: 00-6: 00$ & $1.69977592^{*}$ & 0.0184382 & 0 & 1.643891 & 1.7556608 \\
\hline & $6: 00-9: 00$ & $0.146530082^{*}$ & 0.0224375 & 0 & 0.0785234 & 0.2145367 \\
\hline & 9:00-12:00 & $-0.115414430^{*}$ & 0.0197303 & 0 & -0.1752157 & -0.0556132 \\
\hline & $12: 00-15: 00$ & $-0.328209216^{\star}$ & 0.020464 & 0 & -0.3902342 & -0.2661843 \\
\hline & 15:00-18:00 & $-0.196286002^{\star}$ & 0.020128 & 0 & -0.2572924 & -0.1352796 \\
\hline & 18:00-21:00 & $-0.374455252^{\star}$ & 0.0209598 & 0 & -0.4379828 & -0.3109277 \\
\hline
\end{tabular}

${ }^{\star}$ The mean difference is significant at the 0.05 level.

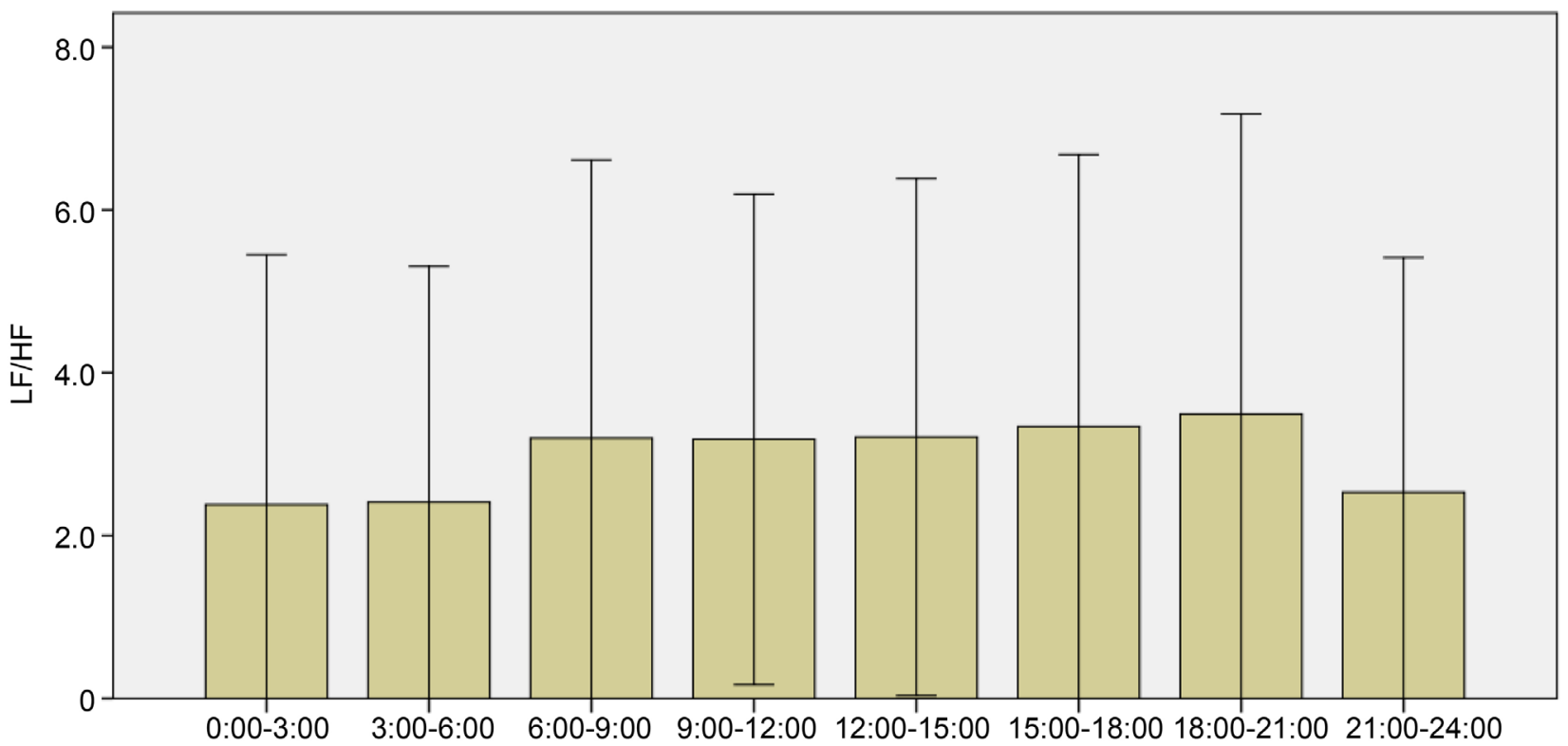

Figure 10. Relationship between LF/HF and circadian rhythm in subjects over 50 years of age.

waking and sleeping decline markedly for subjects aged 50-plus relative to subjects under 50. This supports the trends of previous research indicating growth in sleep time occupied by wake after sleep onset and declining levels of slow- 
Table 8. Relationship between LF/HF and circadian rhythm in subjects over 50 years of age (descriptive statistics).

\begin{tabular}{|c|c|c|c|c|c|c|c|c|}
\hline \multicolumn{9}{|c|}{$\begin{array}{l}\text { Descriptives } \\
\text { LFHF }\end{array}$} \\
\hline & \multirow[t]{2}{*}{$\mathrm{N}$} & \multirow[t]{2}{*}{ Mean } & \multirow[t]{2}{*}{ Std. deviation } & \multirow[t]{2}{*}{ Std. error } & \multicolumn{2}{|c|}{$\begin{array}{l}\text { 95\% Confidence } \\
\text { interval for mean }\end{array}$} & \multirow[t]{2}{*}{ Minimum } & \multirow[t]{2}{*}{ Maximum } \\
\hline & & & & & Lower bound & Upper bound & & \\
\hline 0:00-3:00 & 17,108 & 2.380588839 & 3.069294877 & 0.0234659961 & 2.334593077 & 2.426584600 & 0.0052378176 & 51.12275387 \\
\hline $3: 00-6: 00$ & 17,066 & 2.411597093 & 2.897219037 & 0.0221776466 & 2.368126621 & 2.455067564 & 0.0085205484 & 40.38270518 \\
\hline 6:00-9:00 & 15,535 & 3.197607645 & 3.417184907 & 0.0274165530 & 3.143868002 & 3.251347289 & 0.0078901472 & 49.81408403 \\
\hline 9:00-12:00 & 18,385 & 3.182214489 & 3.011838897 & 0.0222126268 & 3.138675674 & 3.225753304 & 0.0316005655 & 31.97811159 \\
\hline 12:00-15:00 & 18,928 & 3.211938122 & 3.175350653 & 0.0230801872 & 3.166698893 & 3.257177351 & 0.0651674696 & 64.45880871 \\
\hline 15:00-18:00 & 18,440 & 3.339790544 & 3.341343045 & 0.0246059766 & 3.291560550 & 3.388020538 & 0.0520169243 & 44.92429550 \\
\hline 18:00-21:00 & 17,843 & 3.492774616 & 3.688529619 & 0.0276133653 & 3.438649742 & 3.546899489 & 0.0141719790 & 44.61341598 \\
\hline 21:00-24:00 & 16,892 & 2.531507033 & 2.883233297 & 0.0221839689 & 2.488024137 & 2.574989929 & 0.0100680885 & 43.78371076 \\
\hline Total & 140,197 & 2.978154844 & 3.223821687 & 0.0086099703 & 2.961279472 & 2.995030216 & 0.0052378176 & 64.45880871 \\
\hline
\end{tabular}

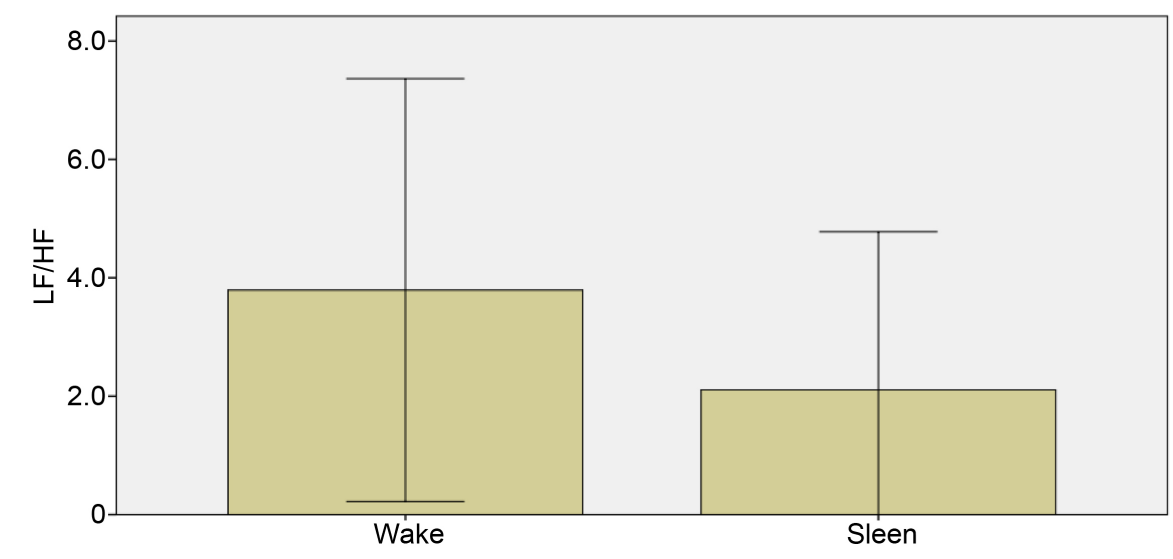

Figure 11. Comparison of LF /HF during sleep and waking in subjects under 50 years of age.

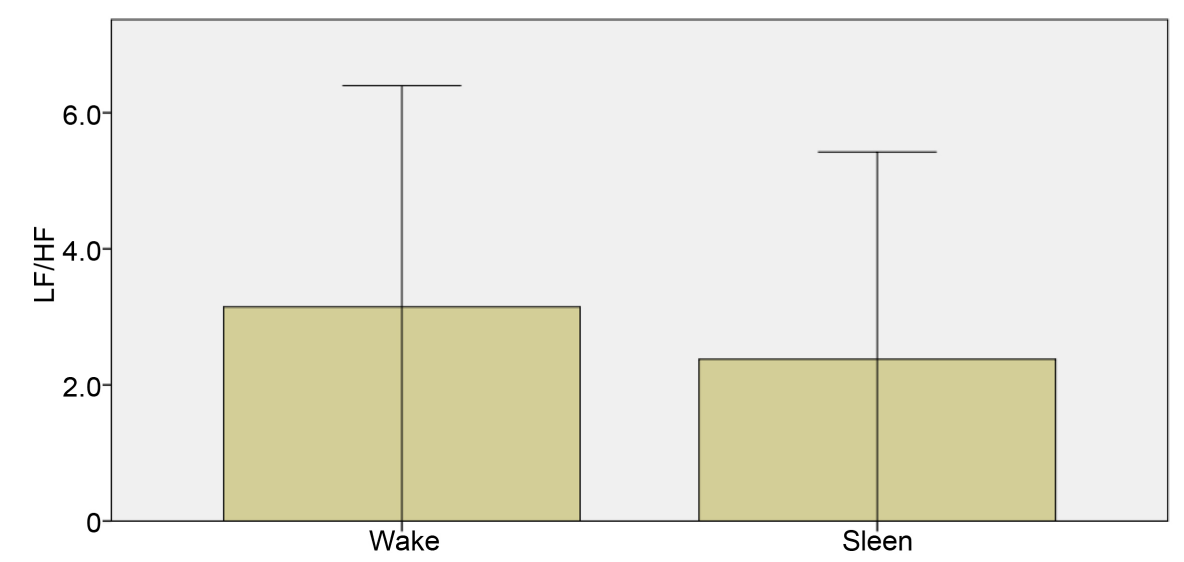

Figure 12. Comparison of LF/HF during sleep and waking in subjects over 50 years of age.

wave sleep in middle- to old-age [27] (Figure 13).

Also, just as changes in autonomic nervous system and endocrine system rhythms, such as reduced secretion of melatonin and cortisol, are reported to be 
Table 9. Relationship between LF/HF and circadian rhythm in subjects over 50 years of age (multiple comparisons).

\begin{tabular}{|c|c|c|c|c|c|c|}
\hline \multicolumn{7}{|c|}{$\begin{array}{l}\text { Multiple comparisons } \\
\text { Dependent variable: LFHF Games-Howell }\end{array}$} \\
\hline \multirow{2}{*}{ (1) Time flag } & \multirow{2}{*}{ (j) Time flag } & \multirow{2}{*}{$\begin{array}{c}\text { Mean } \\
\text { difference (I-J) }\end{array}$} & \multirow{2}{*}{ Std. error } & \multirow{2}{*}{ Sig. } & \multicolumn{2}{|c|}{$95 \%$ Confidence interval } \\
\hline & & & & & Lower bound & Upper bound \\
\hline \multirow[t]{7}{*}{ 0:00-3:00 } & $3: 00-6: 00$ & -0.031008254 & 0.0322877838 & 0.980 & -0.128874716 & 0.0668582088 \\
\hline & $6: 00-9: 00$ & $-0.817018806^{\prime}$ & 0.0360876758 & 0.000 & -0.926403592 & -0.707634021 \\
\hline & 9:00-12:00 & $-0.801625650^{\prime}$ & 0.0323118208 & 0.000 & -0.899564774 & -0.703686527 \\
\hline & $12: 00-15: 00$ & $-0.831349283^{\prime}$ & 0.0329142525 & 0.000 & -0.931114302 & -0.731584265 \\
\hline & $15: 00-18: 00$ & $-0.959201705^{*}$ & 0.0340015743 & 0.000 & -1.06226252 & -0.856140894 \\
\hline & 18:00-21:00 & $-1.11218578^{\prime}$ & 0.0362374242 & 0.000 & -1.22202383 & -1.00234773 \\
\hline & 21:00-24:00 & $-0.150918195^{*}$ & 0.0322921267 & 0.000 & -0.248797849 & -0.053038540 \\
\hline \multirow[t]{7}{*}{$3: 00-6: 00$} & $0: 00-3: 00$ & 0.0310082538 & 0.0322877838 & 0.980 & -0.066858209 & 0.1288747165 \\
\hline & 6:00-9:00 & $-0.786010553^{\prime}$ & 0.0352635135 & 0.000 & -0.892897413 & -0.679123692 \\
\hline & $9: 00-12: 00$ & -0.770617396 & 0.0313886731 & 0.000 & -0.865758369 & -0.675476423 \\
\hline & $12: 00-15: 00$ & $-0.800341030^{\prime}$ & 0.0320084841 & 0.000 & -0.897360593 & -0.703321466 \\
\hline & 15:00-18:00 & $-0.928193451^{*}$ & 0.0331255505 & 0.000 & -1.02859901 & -0.827787889 \\
\hline & 18:00-21:00 & $-1.08117752^{*}$ & 0.0354167468 & 0.000 & -1.18852817 & -0.973826877 \\
\hline & $21: 00-24: 00$ & $-0.119909941^{\prime}$ & 0.0313683995 & 0.003 & -0.214989707 & -0.024830174 \\
\hline \multirow[t]{7}{*}{ 6:00-9:00 } & 0:00-3:00 & $0.817018806^{\star}$ & 0.0360876758 & 0.000 & 0.7076340211 & 0.9264035917 \\
\hline & $3: 00-6: 00$ & $0.786010553^{\prime}$ & 0.0352635135 & 0.000 & 0.6791236922 & 0.8928974129 \\
\hline & 9:00-12:00 & 0.0153931562 & 0.0352855235 & 10.000 & -0.091560263 & 0.1223465749 \\
\hline & $12: 00-15: 00$ & -0.014330477 & 0.0358380024 & 10.000 & -0.122958306 & 0.0942973519 \\
\hline & $15: 00-18: 00$ & $-0.142182899^{\prime}$ & 0.0368391295 & 0.003 & -0.253845082 & -0.030520716 \\
\hline & $18: 00-21: 00$ & $-0.295166970^{\prime}$ & 0.0389122772 & 0.000 & -0.413112904 & -0.177221037 \\
\hline & $21: 00-24: 00$ & $0.666100612^{\star}$ & 0.0352674900 & 0.000 & 0.5592016777 & 0.7729995458 \\
\hline \multirow[t]{7}{*}{$9: 00-12: 00$} & 0:00-3:00 & $0.801625650 "$ & 0.0323118208 & 0.000 & 0.7036865267 & 0.8995647738 \\
\hline & $3: 00-6: 00$ & 0.770617396 & 0.0313886731 & 0.000 & 0.6754764234 & 0.8657583694 \\
\hline & 6:00-9:00 & -0.015393156 & 0.0352855235 & 10.000 & -0.122346575 & 0.0915602626 \\
\hline & $12: 00-15: 00$ & -0.029723633 & 0.0320327307 & 0.983 & -0.126816488 & 0.0673692220 \\
\hline & 15:00-18:00 & $-0.157576055^{\prime}$ & 0.0331489800 & 0.000 & -0.258052451 & -0.057099659 \\
\hline & $18: 00-21: 00$ & $-0.310560127^{\star}$ & 0.0354386615 & 0.000 & -0.417977045 & -0.203143208 \\
\hline & $21: 00-24: 00$ & $0.650707456^{\prime}$ & 0.0313931405 & 0.000 & 0.5555529112 & 0.7458619999 \\
\hline \multirow[t]{7}{*}{$12: 00-15: 00$} & 0:00-3:00 & $0.831349283 "$ & 0.0329142525 & 0.000 & 0.7315842652 & 0.9311143016 \\
\hline & $3: 00-6: 00$ & $0.800341030^{*}$ & 0.0320084841 & 0.000 & 0.7033214665 & 0.8973605926 \\
\hline & $6: 00-9: 00$ & 0.0143304770 & 0.0358380024 & 10.000 & -0.094297352 & 0.1229583059 \\
\hline & $9: 00-12: 00$ & 0.0297236331 & 0.0320327307 & 0.983 & -0.067369222 & 0.1268164883 \\
\hline & 15:00-18:00 & $-0.127852422^{\prime}$ & 0.0337364659 & 0.004 & -0.230109409 & -0.025595435 \\
\hline & 18:00-21:00 & $-0.280836493^{*}$ & 0.0359887897 & 0.000 & -0.389920726 & -0.171752261 \\
\hline & 21:00-24:00 & $0.680431089^{\star}$ & 0.0320128649 & 0.000 & 0.5833982183 & 0.7774639592 \\
\hline \multirow[t]{3}{*}{ 15:00-18:00 } & 0:00-3:00 & $0.959201705^{\star}$ & 0.0340015743 & 0.000 & 0.8561408944 & 1.062262516 \\
\hline & $3: 00-6: 00$ & $0.928193451^{\prime}$ & 0.0331255505 & 0.000 & 0.8277878894 & 1.028599013 \\
\hline & $6: 00-9: 00$ & $0.142182899^{*}$ & 0.0368391295 & 0.003 & 0.0305207160 & 0.2538450818 \\
\hline
\end{tabular}




\section{Continued}

\begin{tabular}{cccccccc}
\hline & $9: 00-12: 00$ & $0.157576055^{\prime}$ & 0.0331489800 & 0.000 & 0.0570996592 & 0.2580524509 \\
$12: 00-15: 00$ & $0.127852422^{\prime}$ & 0.0337364659 & 0.004 & 0.0255954350 & 0.2301094088 \\
& $18: 00-21: 00$ & $-0.152984071^{\prime}$ & 0.0369858355 & 0.001 & -0.265090334 & -0.040877809 \\
& $21: 00-24: 00$ & $0.808283511^{*}$ & 0.0331297836 & 0.000 & 0.7078650920 & 0.9087019292 \\
& $0: 00-3: 00$ & $1.11218578^{\prime}$ & 0.0362374242 & 0.000 & 1.002347727 & 1.222023826 \\
& $3: 00-6: 00$ & $1.08117752^{\prime \prime}$ & 0.0354167468 & 0.000 & 0.9738268772 & 1.188528169 \\
& $6: 00-9: 00$ & $0.295166970^{*}$ & 0.0389122772 & 0.000 & 0.1772210370 & 0.4131129037 \\
& $9: 00-12: 00$ & $0.310560127^{\prime}$ & 0.0354386615 & 0.000 & 0.2031432078 & 0.4179770453 \\
& $12: 00-15: 00$ & $0.280836493^{*}$ & 0.0359887897 & 0.000 & 0.1717522608 & 0.3899207260 \\
& $15: 00-18: 00$ & $0.152984071^{\prime}$ & 0.0369858355 & 0.001 & 0.0408778094 & 0.2650903336 \\
& $21: 00-24: 00$ & $0.961267582^{\prime \prime}$ & 0.0354207061 & 0.000 & 0.8539049150 & 1.068630249 \\
& $0: 00-3: 00$ & $0.150918195^{*}$ & 0.0322921267 & 0.000 & 0.0530385404 & 0.2487978489 \\
& $3: 00-6: 00$ & $0.119909941^{\prime}$ & 0.0313683995 & 0.003 & 0.0248301745 & 0.2149897072 \\
& $6: 00-9: 00$ & $-0.666100612^{*}$ & 0.0352674900 & 0.000 & -0.772999546 & -0.559201678 \\
& $9: 00-12: 00$ & $-0.650707456^{\prime}$ & 0.0313931405 & 0.000 & -0.745862000 & -0.555552911 \\
& $12: 00-15: 00$ & $-0.680431089^{\prime}$ & 0.0320128649 & 0.000 & -0.777463959 & -0.583398218 \\
$15: 00-18: 00$ & $-0.808283511^{\prime}$ & 0.0331297836 & 0.000 & -0.908701929 & -0.707865092 \\
& $18: 00-21: 00$ & $-0.961267582^{\prime \prime}$ & 0.0354207061 & 0.000 & -1.068663025 & -0.853904915 \\
\hline & & & & & &
\end{tabular}

*The mean difference is significant at the 0.05 level.

Table 10. Comparison of LF/HF during sleep and waking in subjects under 50 years of age (group statistics).

\begin{tabular}{ccccc}
\hline & \multicolumn{3}{c}{ Group statistics } \\
\hline & Sleep flag & N & Mean & Std. deviation \\
\hline \multirow{2}{*}{ LFHF } & Wake & 446,392 & 3.793270748 & 3.572033285 \\
& Sleep & 103,351 & 2.106735460 & 2.671197896 \\
\hline
\end{tabular}

Table 11. Comparison of LF/HF during sleep and waking in subjects under 50 years of age (verified by independent sample).

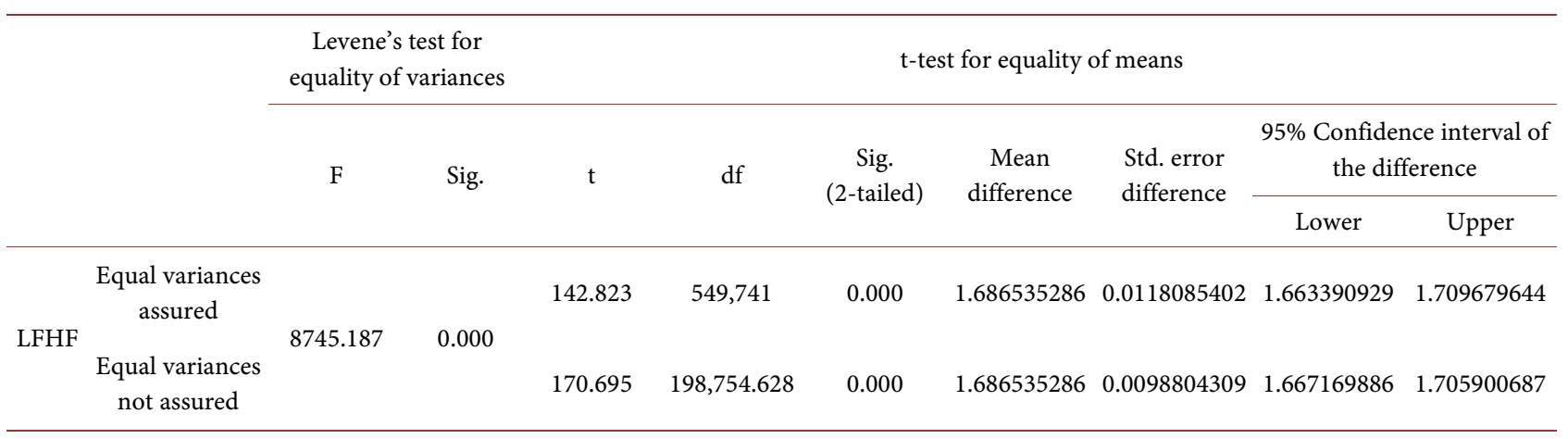

Table 12. Comparison of LF/HF during sleep and waking in subjects over 50 years of age (group statistics).

\begin{tabular}{ccccc}
\hline & \multicolumn{3}{c}{ Group statistics } \\
\hline \multirow{2}{*}{ LFHF } & Sleep flag & $\mathrm{N}$ & Mean & Std. deviation \\
& Wake & 109,651 & 3.145304198 & 3.252340387 \\
& Sleep & 30,546 & 2.378138678 & 3.044673392 \\
\hline
\end{tabular}


Table 13. Comparison of LF/HF during sleep and waking in subjects over 50 years of age (verified by independent sample).

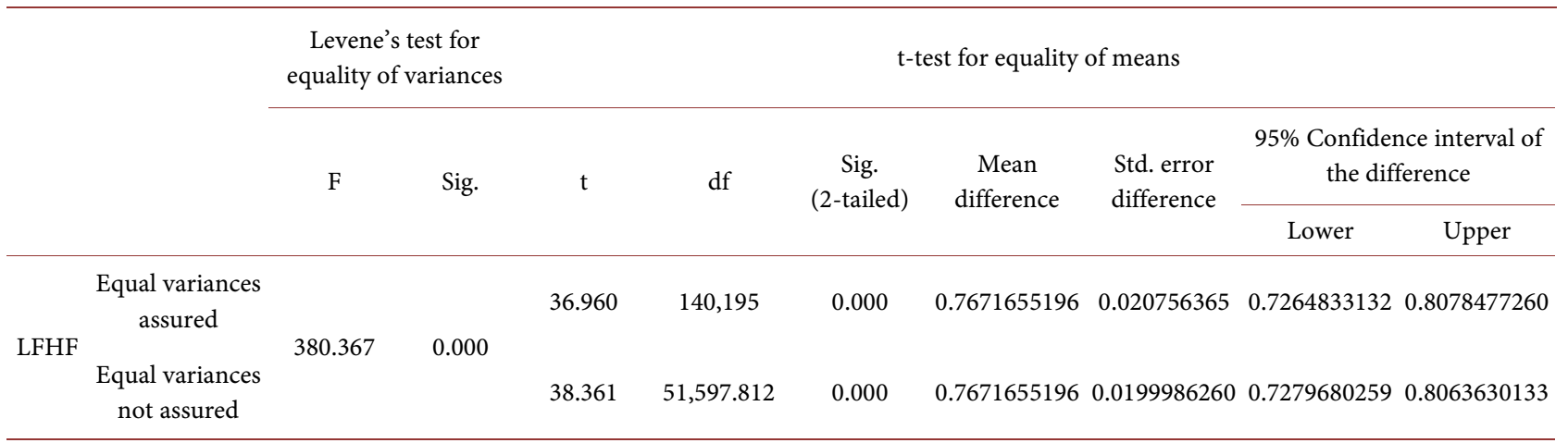

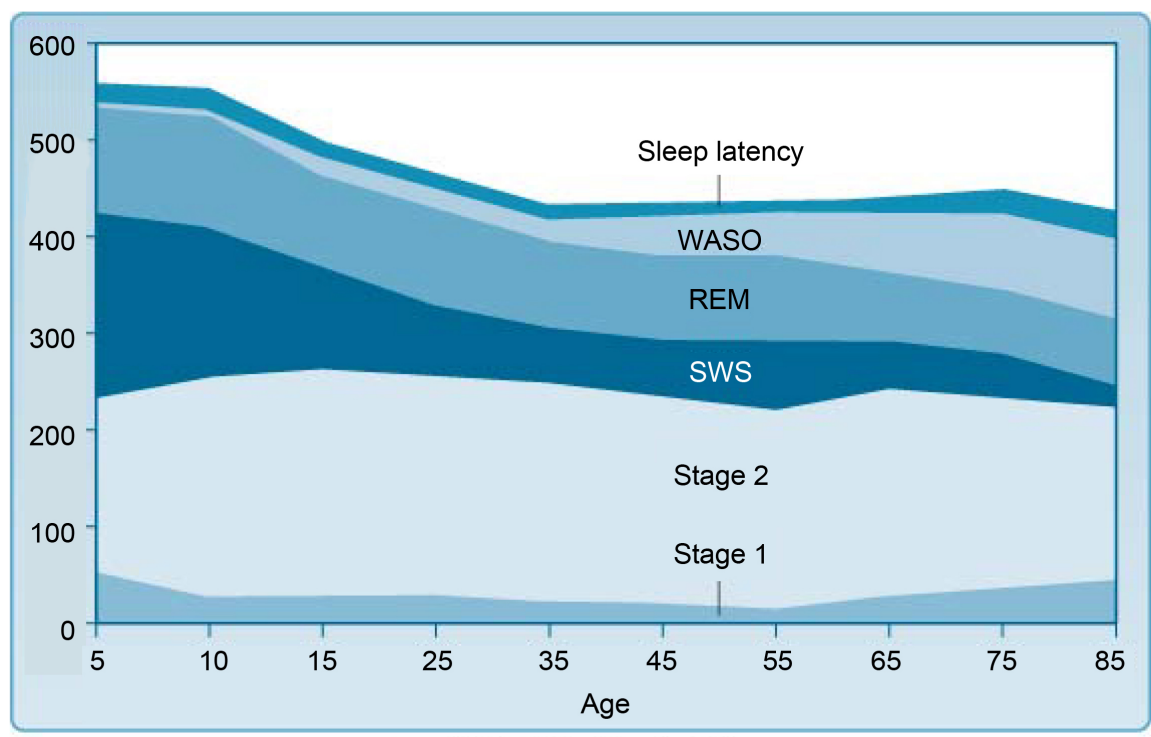

Copyright 2005 by Elsevier Science

Figure 13. Relationship between age and sleep.

age-related [28], in this study also there was a trend that suggests a decrease with age in autonomic nervous function while sleeping as one of the causes.

\section{Conclusions}

Long-term monitoring of autonomic nerve function of 600 subjects across all age groups as they went about their daily lives revealed the following:

$>$ The LF/HF ratio, an indicator of autonomic nerve balance, demonstrated a tendency to peak in the 40 's and decline thereafter, conceivably due partially to causes of concern and stress changing and declining for individuals aged 50-plus.

Diurnal variation of autonomic nerve activity tended to decline for subjects aged 50-plus, exhibiting a tendency for a drop in rising sympathetic nerve activity function particularly in the morning, which may conceivably stem from declining responsiveness of the autonomic nervous system.

Differences in autonomic nerve activity between sleeping and waking hours exhibited a tendency to decline in subjects aged 50-plus, which is consistent 
with the tendency for rising levels of wake after sleep onset and declining levels of slow-wave sleep in middle- to old-age.

Moving forward, we hope to examine what kind of differences emerge in these trends as well as see how the conclusions reached herein change as the result of adding correlational analysis with other biological indicators such as saliva and brain waves.

\section{References}

[1] Health, Labour, and Welfare Ministry (Japan) (2010) Review of National Livelihood Survey: The State of Stress and Concerns.

[2] Onaka, T. (2005) Stress and Its Neural Mechanisms. Journal of Pharmacological Sciences, 126, 170-173.

[3] Robertson, D. (2007) Primer on the Autonomic Nervous System. Takahashi, A. and Mano, T., Trans., Elsevier, Japan.

[4] Beck, A.T., Ward, C.H., Mendelson, M., et al. (1961) An Inventory for Measuring Depression. Archives of General Psychiatry, 4, 561-571. https://doi.org/10.1001/archpsyc.1961.01710120031004

[5] Samejima, K., Matsushita, K. and Matsumoto, K. (1976) An Evaluation of Explicit Anxiety in Depressives and Healthy Subjects (MAS) and Clinical Study of the Beck Depression Inventory (BDI). Japanese Society of Psychosomatic Medicine, 311-319.

[6] Zung, W.W.K. (1965) A Self-Rating Depression Scale. Archives of General Psychiatry, 12, 63-70. https://doi.org/10.1001/archpsyc.1965.01720310065008

[7] Fukuda, K. and Kobayashi, S. (1973) An Evaluation of Self-Rating Depression Scales. Official Journal of the Japanese Society of Psychiatry and Neurology, 75, 673-679.

[8] Radloff, L.S. (1977) The CES-D Scale: A Self-Report Depression Scale for Research in the General Population. Applied Psychological Measurement, 1, 385-401. https://doi.org/10.1177/014662167700100306

[9] Shima, S. and Shiga, N., Kitamura, T., et al. (1985) New Self-Rating Depression Scales. Japanese Society of Psychosomatic Medicine, 27, 717-723.

[10] Yamaguchi, M. (2007) Measuring Stress with Salivary Markers. Journal of Pharmacological Sciences, 129, 80-84.

[11] Schiepers, O.J., Wichers, M.C. and Maes, M. (2005) Cytokines and Major Depression. Progress in Neuro-Psychopharmacology \& Biological Psychiatry, 29, 201-217. https://doi.org/10.1016/j.pnpbp.2004.11.003

[12] Motonori, I. and Tomoyuki, Y. (2000) The Relationship between Brain Wave Fluctuation and Reaction Times with the Decrease in Arousal Level. Ergonomics, 36, 229-237.

[13] Association between Images of Mental State and Heart-Rate Variability (2005) Assessment of Depression Severity by Power Spectral Analysis; Toshihiro Fujioka (Keiaikai Jozan Hospital, Department of Psychiatry), Yumiko Mori (0288-9250). Autonomic Nerves, 42, 191-192.

[14] Sugaya, J., Fukuma, N., Ushijima, A., Kato, Y., Aisu, T., Tsuchida, T., Takahashi, K., Kishida, H. and Mizuno, K. (2009) Relationship between Depression and Prognostic Factors in Cases of Mild Heart Attack. The Journal of the Japanese Coronary Association, 15, 198-201.

[15] Ohira, T., Diez Roux, A.V., Prineas, R.J., et al. (2008) Associations of Psychosocial Factors with Heart Rate and Its Short-Term Variability: The Multi-Ethnic Study of 
Atherosclerosis. Psychosomatic Medicine, 70, 141-146. https://doi.org/10.1097/PSY.0b013e318160686a

[16] Yukishita, T., Lee, K., Kim, S., Yumoto, Y., Kobayashi, A., Shirasawa, T. and Kobayashi, H. (2010) Age and Sex-Dependent Alterations in Heart Rate Variability: Profiling the Characteristics of Men and Women in Their 30s. Anti-Aging Medicine, 7, 94-100. https://doi.org/10.3793/jaam.7.94

[17] Task Force of the European Society of Cardiology and the North American Society of Pacing and Electrophysiology (1996) Heart Rate Variability: Standards of Measurement, Physiological Interpretation, and Clinical Use. Circulation, 93, $1043-$ 1065. https://doi.org/10.1161/01.CIR.93.5.1043

[18] Kuratsune, H. (2011) Establishment of Objective Methods for Fatigue Diagnosis and Creation of Policies for the Diagnosis of Chronic Fatigue for Patients Complaining of Chronic Fatigue Associated with Autonomic Nerve Irregularities Health Labor Sciences Integrated Research Center for the Disabled (Mental Disability/ Nerve \& Muscle Division) Integrated Research Reports from 2009-2011. 1-114.

[19] Oguma, Y., Yamamoto, S., Kinoshita, N., Katsukawa, F., Onishi, S. and Yamazaki, H. (1999) Fundamental Examination of Assessing 1 Body Activity and Intensity of Body Activity Using a Triaxial Accelerometer Simultaneously Recording HeartRate. Keio University Sports Medicine Research Center Bulletin, 25-31.

[20] Matsumura, Y., Yamamoto, M., Kitado, M., Nakamura, H., Hondera, K. and Fujimoto, S. (2008) High-Precision Body Monitoring Using Triaxial Acceleration Sensor. Matsushita Denko Giho, 56, 60-66.

[21] (2007) Triaxial Acceleration Sensor Application Notes. Hokuriku Electric Works Co.

[22] Pomeranz, B., Macaulay, R.J., Caudill, M.A., Kutz, I., Adam, D., Gordon, D., Kilborn, K.M., Barger, A.C., Shannon, D.C. and Cohen, R.J. (1985) Assessment of Autonomic Function in Humans by Heart Rate Spectral Analysis. American Journal of Physiology, 248, H151-H153.

[23] Hayano, J., Sakakibara, Y., Yamada, M., Kamiya, T., Fujinami, T., Yokoyama, K., Watanabe, Y. and Takata, K. (1991) Accuracy of Assessment of Cardiac Vagal Tone by Heart Rate Variability in Normal Subjects. American Journal of Cardiology, 15, 199-204.

[24] Zhang, J. (2007) Effect of Age and Sex on Heart Rate Variability in Healthy Subjects. Journal of Manipulative and Physiological Therapeutics, 30, 374-379. https://doi.org/10.1016/j.jmpt.2007.04.001

[25] Parashar, R., Amir, M., Pakhare, A., Rathi, P. and Chaudhary, L. (2014) Age Related Changes in Autonomic Functions. Journal of Clinical and Diagnostic Research, 10 , CC11.

[26] Shimazu, T., et al. (2005) Aging of the Autonomic Nervous System. Nippon Rinsho, 63, 973-977.

[27] (2005) Principles and Practice of Sleep Medicine. 4th Edition, Elsevier, Amsterdam.

[28] Van Coevorden, A., Mockel, J., Laurent, E., Kerkhofs, M., L’Hermite-Baleriaux, M., Decoster, C., et al. (1991) Neuroendocrine Rhythms and Sleep in Aging Men. American Journal of Physiology, 260, E651-E661. 
Submit or recommend next manuscript to SCIRP and we will provide best service for you:

Accepting pre-submission inquiries through Email, Facebook, LinkedIn, Twitter, etc. A wide selection of journals (inclusive of 9 subjects, more than 200 journals)

Providing 24-hour high-quality service

User-friendly online submission system

Fair and swift peer-review system

Efficient typesetting and proofreading procedure

Display of the result of downloads and visits, as well as the number of cited articles Maximum dissemination of your research work

Submit your manuscript at: http://papersubmission.scirp.org/

Or contact health@scirp.org 